POLICY DISCUSSION PAPERS

\title{
Inflation and Welfare: A Search Approach
}




\section{Inflation and Welfare: A Search Approach}

By Ben Craig and Guillaume Rocheteau

This paper extends recent findings in the search-theoretic literature on monetary exchange regarding the welfare costs of inflation. We present first some estimates of the welfare cost of inflation using the "welfare triangle" methodology of Bailey (1956) and Lucas (2000). We then derive a money demand function from the search-theoretic model of Lagos and Wright (2005) and we estimate it from U.S. data over the period 1900-2000. We show that the welfare cost of inflation predicted by the model accords with the welfare-triangle measure when pricing mechanisms are such that buyers appropriate the social marginal benefit of their real balances. For other mechanisms, welfare triangles underestimate the true welfare cost of inflation because of a rent-sharing externality. We also point out other inefficiencies associated with noncompetitive pricing, which matter for estimating the cost of inflation. We then illustrate how endogenous participation decisions can mitigate or exacerbate the cost of inflation, and we provide calibrated examples in which a deviation from the Friedman rule is optimal. Finally, we discuss distributional effects of inflation.
Ben Craig is an economic advisor at the Federal Reserve Bank of Cleveland, and Guillaume Rocheteau is an economist at the Bank. The authors have benefited from the comments of Ray Batina, Chuck Carlstrom, Richard Dutu, Sebastien Lotz, Ed Nosal, and Christopher Waller. They thank Patrick Higgins for his research assistance and Monica Crabtree-Reusser for editorial assistance.

Materials may be reprinted, provided that the source is credited. Please send copies of reprinted materials to the editor.

Policy Discussion Papers are published by the Research Department of the Federal Reserve Bank of Cleveland. To receive copies or to be placed on the mailing list, e-mail your request to 4dsubscriptions@clev.frb.org or fax it to 216-579-3050. Please send your questions comments, and suggestions to us at editor@clev.frb.org.

Policy Discussion Papers are available on the Cleveland Fed's site on the World Wide Web: www.clevelandfed.org/Research.

Views stated in Policy Discussion Papers are those of the authors and not necessarily those of the Federal Reserve Bank of Cleveland or of the Board of Governors of the Federal Reserve System. 


\section{Introduction}

Assessing the welfare costs of inflation requires a sound understanding of the benefits of monetary exchange. The search theory of money, developed in the last 15 years from the pioneering works of Kiyotaki and Wright $(1989,1991,1993)$, offers such a framework. However, the first generation of search models of money were based on assumptions that were too restrictive to be able to deliver useful insights for monetary policy (goods and money were indivisible, for example, individuals' portfolios were limited to one unit of one object, and so forth).These severe restrictions have been relaxed in several recent extensions of the theory, by Shi (1997, 1999), Molico (1999), and Lagos and Wright (2005).The extensions have opened up the perspectives for a better understanding of the costs, and also maybe benefits, associated with inflationary finance.As an example, Lagos and Wright provide estimates for the cost of 10 percent inflation ranging from 1.4 percent of GDP to 4.6 percent of GDP. Interestingly, these numbers are significantly larger than estimates based on the traditional method developed by Bailey (1956), which consists of computing the area underneath a money demand function. For instance, Lucas (2000), using Bailey's approach, estimates the cost of 10 percent inflation at slightly less than 1 percent of GDP. ${ }^{1}$

In this paper we clarify and extend recent findings provided by models of monetary exchange to the evaluation of the cost of inflation for society. Our approach consists of relating the measures of the welfare cost of inflation obtained from different versions of the search-theoretic model of Lagos and Wright (2005) with the traditional measures based on the area underneath the money demand function. We show the conditions under which the two measures are consistent, and those under which they differ. We also disentangle the different effects of inflation in search models of monetary exchange: a real-balance effect, an effect on participation decisions, and a distributional effect. We show that the estimates for the welfare cost of inflation provided by the basic version of the search model of Lagos and Wright coincide with those provided by the Bailey method whenever money holders can appropriate the marginal social return of their real balances. This condition is satisfied when buyers have all the bargaining power to set prices in bilateral trades, or when pricing is competitive. If this condition does not hold, then the welfare cost of inflation is larger than what traditional estimates predict. This discrepancy arises because of a rent-sharing externality associated with noncompetitive pricing mechanisms. We establish a simple relationship between the cost of inflation, the area underneath the money demand function, and the buyer's share in the surplus of a trade. We also discuss various inefficiencies associated with different bargaining solutions.

We also extend the Lagos-Wright model by introducing participation decisions and trading frictions. We show that the measures of the cost of inflation based on the Bailey methodology are in general misleading since they do not take into account the effects of inflation on participation decisions. We also illustrate how the presence of search frictions can mitigate or exacerbate the welfare cost of inflation. We provide calibrated examples in which the Friedman rule, where the interest rate is set to zero, is not the optimal policy.

The Lagos-Wright model is based on assumptions that yield a degenerate distribution of money balances in equilibrium. ${ }^{2}$ While these assumptions make the model tractable, they prevent an analysis of the distributional effects of inflation. We reintroduce such effects by considering a simple extension of the Lagos-Wright model in which agents receive idiosyncratic productivity shocks. We discuss the distributional effects of monetary policy and the insurance role of inflation.
1. Based on this methodology, Fischer (1981) and Lucas (1981) obtained estimates for the cost of 10 percent inflation ranging from 0.3 percent of GDP to 0.45 percent of GDP.
2. Shi $(1997,1999)$ constructs a different model, which also yields a degenerate distribution of money balances. The economy is populated by households composed of a large number of members, who pool their money balances at the end of each period. See also Faig (2004). 
The paper is organized as follows. First, we present the methodology Bailey (1956) developed to compute the welfare cost of inflation. Next, we use a search-theoretic model to derive a money demand function, and we fit this function to the data. This allows us to compute an alternative measure of the cost of inflation and to compare it to the Bailey estimates. Then, the benchmark model is extended to discuss the importance of pricing mechanisms. Next, we consider participation decisions and search frictions. Finally, we introduce the distributional effects of inflation. ${ }^{3}$

\section{The "Welfare Triangle"}

The traditional approach to measuring the cost of inflation was developed by Bailey (1956).The estimates provided by this approach will be useful in explaining some findings of the search model. Bailey (1956) measures the welfare cost of inflation by calculating the area underneath a money demand curve over an appropriate interval. We plot in figure 1 the (inverse) demand for real balances, where the cost of holding real balances, the nominal interest rate, is represented on the vertical axis.The demand for real balances is downward-sloping since individuals reduce their money balances and resort to alternative payment arrangements, such as credit or barter, as the interest rate increases. The area underneath the money demand relationship over the interval $\left[m_{1}, m^{*}\right]$, the "triangle" $A B C$ in figure 1 , measures the welfare cost of having a positive interest rate $r_{1}$ instead of zero. (In this analysis, the interest rate is assumed to vary one to one with the inflation rate.) Obviously, the welfare cost of inflation is minimized when the nominal interest rate is zero. ${ }^{4}$ This corresponds to the Friedman (1969) rule for optimal monetary policy. In the following, we will measure the cost of inflation as the cost of raising the interest rate from $r_{0}=3$ percent, interpreted as the interest rate consistent with zero inflation, to $r_{1}$, say, the interest rate associated with 10 percent inflation. Graphically, this cost is measured by the area $A B D E$.

We define monetary assets according to the monetary aggregate M1, that is, currency and demand deposits. ${ }^{5}$ Money demand is then defined by the aggregate money balances M1 divided by nominal gross domestic product. ${ }^{6}$ The nominal interest rate, $r$, is measured by the short-term commercial paper rate. In figure 2, we represent each observation $(r, m)$ by a circle for the period 1900-2000.

\section{\begin{tabular}{l|l} 
FIGURE 1 & THE WELFARE TRIANGLE
\end{tabular}}

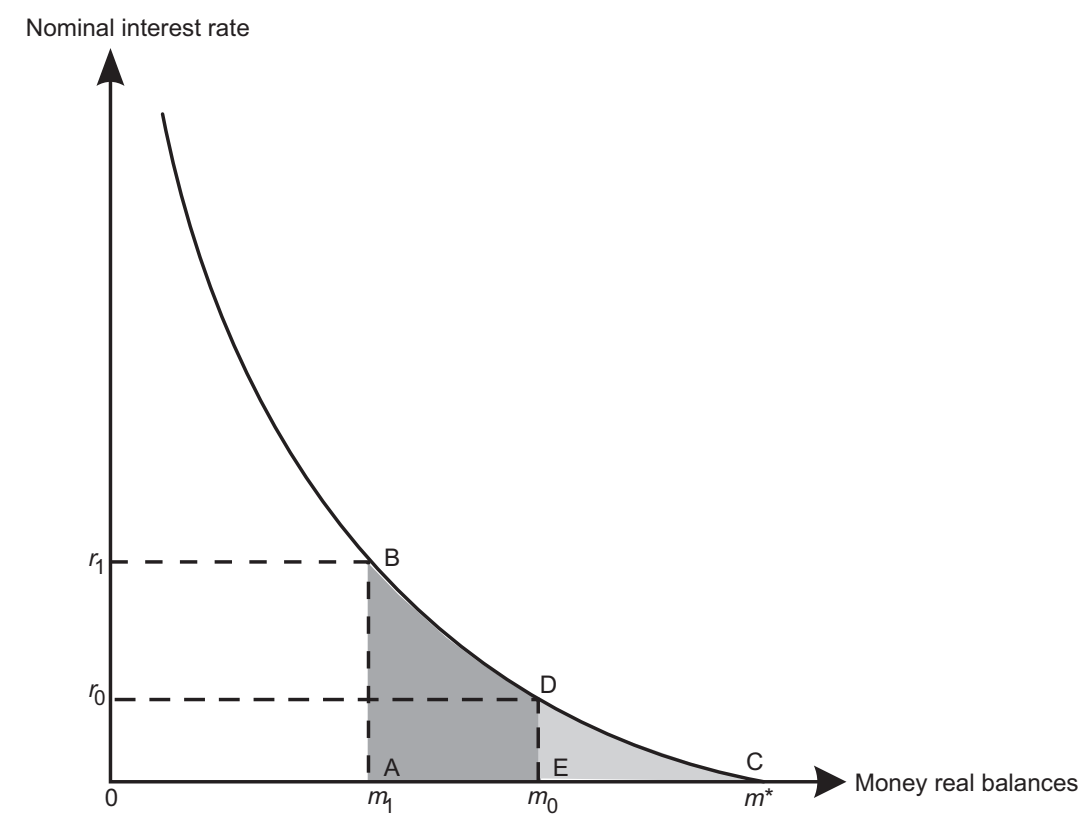

3. A more detailed presentation of the model occurs in appendix 1 , and the data are given in appendix 2.

4. Since the interest rate is approximately the sum of a constant real interest rate and the inflation rate, the Friedman rule would imply that the inflation rate is negative and approximately equal to the opposite of the real interest rate.

5. Alternatively, several authors, including Fischer (1981), define money as high-powered money. The operational definition of monetary assets is somewhat arbitrary. For a discussion, see Lucas (1981) and Marty (1999).

6. By measuring real balances as a fraction of domestic output, the area of the money triangle can be interpreted as the fraction of income that is needed to compensate individuals for an interest rate of $r_{1}$ instead of zero (Lucas, 2000). 
To measure the welfare triangle, one estimates a curve that fits the observations in figure 2 , and then computes the appropriate area underneath the implied money demand curve. Lucas (2000) considers two specifications for money demand: the $\log -\log$ specification, $m(r)=A r^{-\eta}$, where $m$ is aggregate real balances divided by output, $r$ is the interest rate, and $A$ and $\eta$ are two estimated parameters; and the semilog specification, where $m(r)=A e^{-\eta r}$. In order to estimate the parameters $A$ and $\eta$ we use nonlinear least squares. ${ }^{7}$ We also estimate the money demand curve by using a kernel regression. ${ }^{8}$

It can be seen in figure 3 that the welfare cost associated with an interest rate of 13 percent (10 percent inflation, approximately) is quite different across specifications for the money demand function, from slightly more than 0.5 percent to slightly less than 1.5 percent. These differences simply reflect different ways to fit the data.According to the R-squared criterion, the best fit is obtained for the kernel regression which evaluates the cost of 10 percent inflation at about 1 percent of GDP. 9 This number is similar to Lucas's measure.The estimate from the semilog specification, about 1.5 percent of GDP, is comparable to Lagos and Wright's smallest estimate of the welfare cost of inflation.

\section{Search for a Money Demand Curve}

The Bailey approach does not identify explicitly the benefits of monetary exchange for society. ${ }^{10}$ An alternative approach consists of constructing a microfounded model economy in which money has an essential role in trades, so that there is a well-specified demand for real balances and a natural measure of welfare. A theory that emphasizes the transactional role of money is the search approach of monetary exchange pioneered by Kiyotaki and Wright $(1989,1991,1993)$. The recent extension proposed by Lagos and Wright (2005) describes an economy in which trades take place under different market structures. Some trades occur in a decentralized (or search) market, where buyers and sellers are matched bilaterally, and other trades occur in a centralized market. Money is useful because of a standard double-coincidence-of-wants problem in the decentralized market:The buyer does not produce a good that the seller wants to consume.

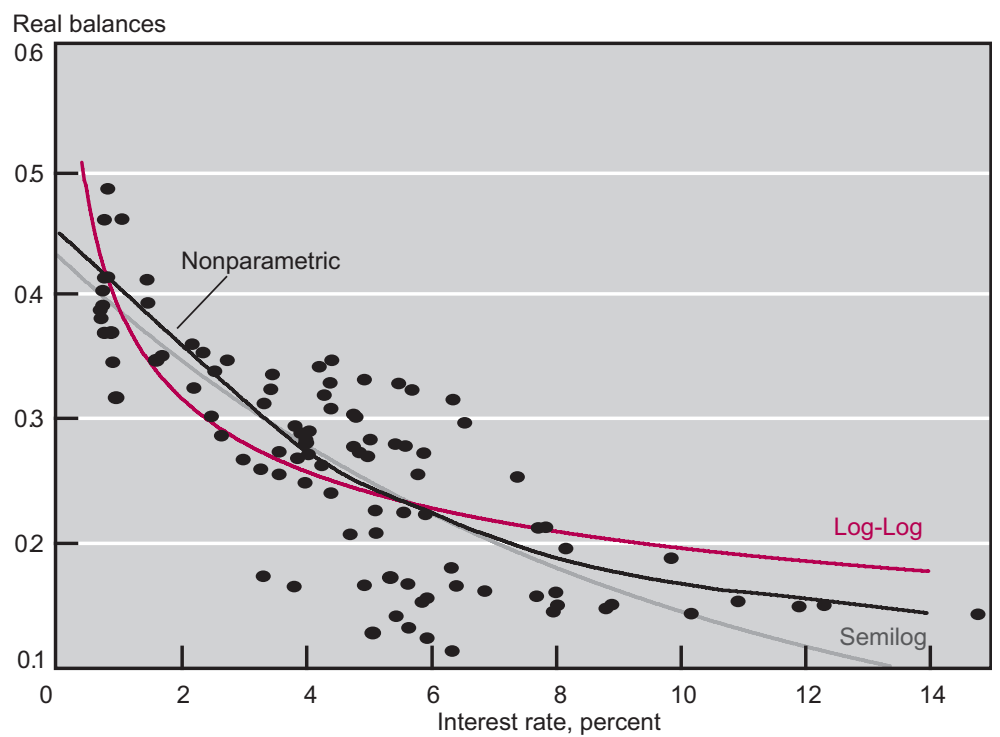


The instantaneous utility of an agent is $u\left(q^{b}\right)-c\left(q^{s}\right)+x$, where $q^{b}$ is the consumption and $q^{s}$ is the production in a bilateral match, and $x$ is the net consumption in the centralized market ( $x$ is negative if an agent produces more at night than he consumes). ${ }^{11}$ The probability of a single-coincidenceof-wants meeting in which an agent meets someone who produces a good he likes is $\sigma \leq 1 / 2$. There are no double-coincidence-of-wants meetings in which agents could use barter. So with probability $\sigma$ an agent is a buyer in a bilateral match, with probability $\sigma$ he is a seller, and with probability $1-2 \sigma$ he is unmatched.A social planner, who would dictate the quantities to produce and consume, would choose $q^{b}=q^{s}=q^{*}$, where $q^{*}$ satisfies $u^{\prime}\left(q^{*}\right)=c^{\prime}\left(q^{*}\right)$. The socially efficient level of production and consumption in the centralized market is indeterminate. The quantity of fiat money in the economy is growing at a constant rate, $\pi$, through lump-sum transfers in the centralized market.

Denote $z(q)$ as the real balances that an agent must hold in order to buy the quantity $q \in\left[0, q^{*}\right]$ in a bilateral match. The specific form for $z(q)$ will depend on the assumed pricing mechanism in the decentralized market.The Lagos-Wright model can be reduced to one equation that specifies the quantity $q=q^{b}=q^{s}$ traded in bilateral matches. This equation says that an agent chooses the quantity $q$ to consume in the decentralized market so as to maximize the expected surplus he gets as a buyer, $\sigma[u(q)-z(q)]$ minus the cost of holding real balances, $r z(q)$,

$q=\arg \max \{-r z(q)+\sigma[u(q)-z(q)]\}$.

In order to calibrate the model, we adopt the same functional forms as the ones used in LagosWright: $u(q)=q^{1-\eta} /(1-\eta)$, where $\eta \geq 0$ and $c(q)=q$. Furthermore, the matching probability $\sigma$ is set to $1 / 2$, so that each agent trades with probability one. Half of the time an agent is a buyer, and half of the time he is a seller. ${ }^{12}$ The money demand function that is estimated is defined as aggregate money balances divided by aggregate nominal output. It is equal to $L=z /(\sigma z+A)$, where $A$ is the real output in the centralized market (this quantity is indeterminate in the model) and where $z$ is a function of the nominal interest rate, $r{ }^{13}$
11. The linearity of the preferences is what guarantees that the distribution of wealth at the beginning of each period is degenerate. Intuitively, this linearity eliminates wealth effects in the choice of real balances and ensures that all buyers carry the same amount of real balances.
12. Alternatively, one could consider a model in which half of the agents are buyers in even periods and the remaining half are buyers in odd periods. This formulation would give identical results for the cost of inflation.

\section{FIGURE 3}

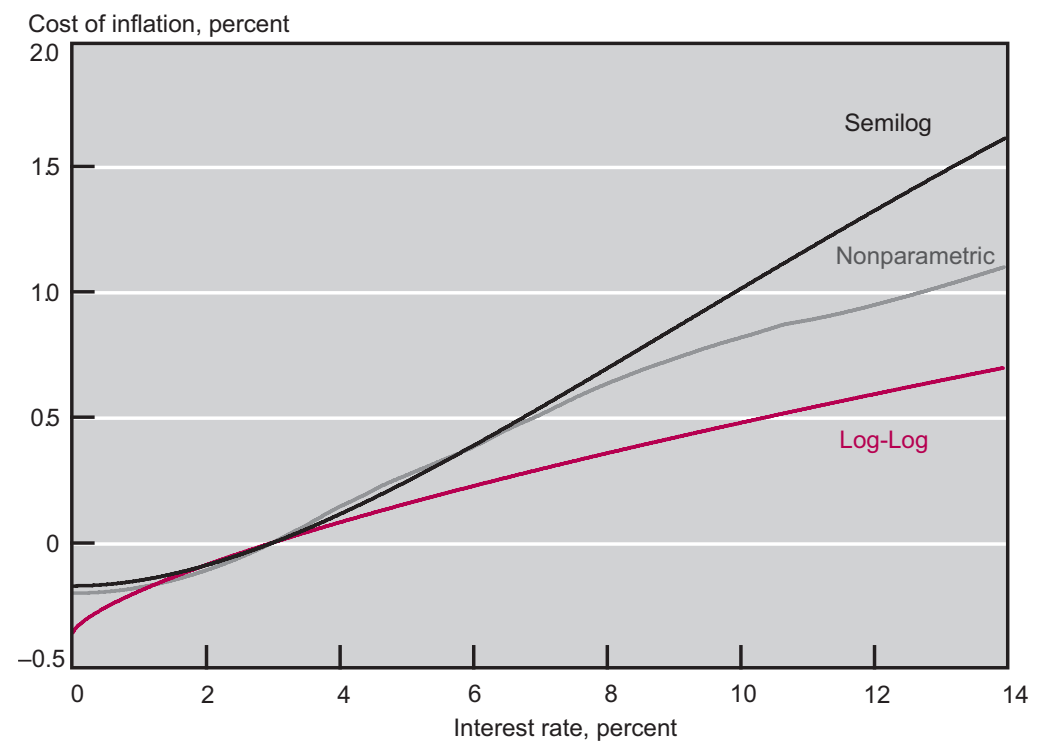

13. Since agents readjust their real balances in the centralized market, the output $A$ must be at least equal to $\sigma z$. 
One needs to take a stand on how prices (or terms of trade) are determined in decentralized markets in which buyers and sellers are matched bilaterally. We will assume here that the monetary transfer from the buyer to the seller is such that the seller is exactly compensated for his production cost, $z(q)=c(q)$. This bargaining solution, called the dictatorial solution, is the outcome of a game in which the buyer makes an offer which the seller can accept or reject. If the offer is rejected, no trade takes place.After some calculation, aggregate real balances satisfy

$$
L=\left[\sigma+A\left(1+\frac{r}{\sigma}\right)^{\frac{1}{\eta}}\right]^{-1}
$$

As in the previous section, the parameters $A$ and $\eta$ can then be estimated from the data for the U.S. economy from 1900 to 2000.The parameter $A$ could be interpreted as the extent of the tax base. The parameter $\eta$ represents the sensitivity of individual real balances to changes in the interest rate.

In order to measure the welfare cost associated with a given interest rate, $r$, relative to 3 percent (the interest rate consistent with zero inflation), we ask the following question. What is the percentage of total consumption that individuals would be willing to sacrifice in order to be in the steady state with an interest rate of 3 percent instead of the steady state associated with $r$ ?

In figure 4, we compare the two measures of the welfare cost of inflation, namely, the compensated measure and the welfare triangle measure. The welfare triangle measure is the area underneath the money demand function as estimated from the search model. Figure 4 shows that the two measures are nearly identical. In order to understand this result, consider the individual demand for real balances given by

$r=\sigma\left[u^{\prime}(q) \frac{d q}{d z}-1\right]$

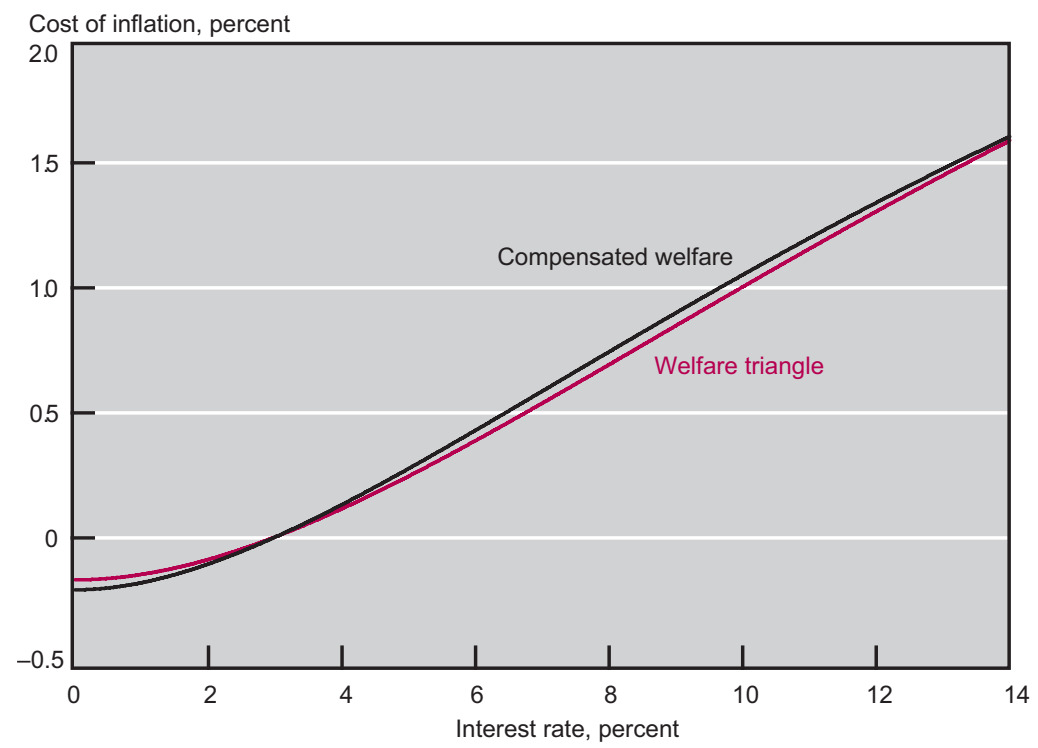


where $d q / d z=1 / z^{\prime}(q)$. Compute the area underneath this money demand function over the interval $\left[z_{0}, z_{1}\right]$

$$
\int_{z_{0}}^{z_{1}} r(z) d z=\sigma\left\{u\left[q\left(z_{1}\right)\right]-z_{1}\right\}-\sigma\left\{u\left[q\left(z_{0}\right)\right]-z_{0}\right\}
$$

Using the assumed dictatorial solution, where the seller is exactly compensated for production costs, $z=c(q)$, it is easy to see that the right-hand side of the previous expression is just the change in steady-state welfare. So the area underneath the individual demand for real balances coincides with the change in steady-state welfare. These two measures do not exactly coincide in figure 4 because we express real balances as a fraction of aggregate output and we do not look at the change in steadystate welfare but at a compensated measure of welfare.

The welfare cost of a nominal interest rate of 13 percent relative to a 3 percent interest rate is about 1.5 percent. ${ }^{14}$ This measure is bigger than the ones of Lucas (2000) but it accords with the nonlinear least square estimate based on the semilog specification. The difference between the numbers simply stems from different strategies of fitting the points in the data. In all cases, the cost of inflation corresponds to the area underneath a money demand function. ${ }^{15}$

\section{Pricing}

The estimate for the welfare cost of inflation in the previous section has been obtained by assuming a special pricing mechanism: Buyers are able to extract the whole surplus from trade.Alternatively, one can model prices, and the way in which the surplus from a trade is shared between trading partners, differently. In this section, we consider first a simple bargaining solution, called the proportional solution, which will illustrate the role played by the pricing mechanism in assessing the welfare cost of inflation. The proportional bargaining solution assumes that the buyer obtains a constant fraction, called the buyer's share and denoted $\theta$, of the surplus of a match defined as the difference between the buyer's utility of consumption and the seller's disutility of production. Formally, $u(q)-z(q)=\theta[u(q)-c(q)]$, and therefore $z(q)=\theta c(q)+(1-\theta) u(q)$. The dictatorial solution of the previous section corresponds to $\theta=1$. From the agent's choice of real balances, one can find a simple relationship between $z$, individual real balances, and the nominal interest rate, $r$. Aggregate real balances are defined as $L=z /(\sigma z+A)$.

We use the same method as before to derive the cost of inflation: We estimate the parameters $A$ and $\eta$ of money demand generated by the model, and we use compensated welfare to compute the cost of inflation. In figure 5, we report the welfare cost of inflation for different values for the buyer's share $(\theta=0.3,0.5,0.8,1) .{ }^{16}$ When the buyer's share is less than 1 , the cost of inflation is typically larger than the measure given by the money triangle. In fact, the area of the welfare triangle is approximately equal to the buyer's share multiplied by the compensated measure of the welfare cost of inflation. For instance, if the buyer's share is 50 percent, the welfare cost of inflation is always about twice the size of the area of the money triangle (see figure 6). To understand this result, consider the area underneath the individual demand for real balances. It satisfies

$$
\begin{aligned}
\int_{z_{0}}^{z_{1}} r(z) d z & =\sigma\left\{u\left[q\left(z_{1}\right)\right]-z_{1}\right\}-\sigma\left\{u\left[q\left(z_{0}\right)\right]-z_{0}\right\} \\
& =\theta \sigma\left\{u\left[q\left(z_{1}\right)\right]-c\left[q\left(z_{1}\right)\right]\right\}-\theta \sigma\left\{u\left[q\left(z_{0}\right)\right]-c\left[q\left(z_{0}\right)\right]\right\}
\end{aligned}
$$

14. Assuming a competitive pricing mechanism, Rocheteau and Wright $(2004,2005)$ and Reed and Waller (2004) find similar estimates for the welfare cost of inflation, between 1 and 1.5 percent of GDP.

15. Aiyagari, Braun, and Eckstein (1998) also show, using a cash-in-advance model with a credit sector, that the welfare cost of inflation using an estimated money demand curve is consistent with the prediction of the model.

16. The $\mathrm{R}^{2}$ for the case of $\theta=1.0$ is 0.6757 , which is higher than the $\log -\log$ and semilog parametric models above. Other values of $\theta$ gave smaller values for the $\mathrm{R}^{2}$ than the semilog model. 
It is equal to the change in steady-state welfare multiplied by $\theta$.In figure 6 , real balances are divided by aggregate output, and the welfare metric of the model is a compensated measure, which explains the slight discrepancy between the two lines.

As one varies the buyer's share from 0.3 to 1 , the cost of 10 percent inflation varies from slightly more than 1 percent to 6 percent of GDP. In order to understand why the welfare triangle can underestimate the true welfare cost of inflation, consider the following example. Suppose that each unit of good produced in a bilateral match is worth $\$ 1$ for the buyer and costs $\$ 0.9$ to produce. The marginal surplus of a trade is then $\$ 0.1$. Suppose that the price is $\$ 0.95$, so that both the buyer and the seller get a surplus of $\$ 0.05$. The private return of money is equal to the buyer's surplus divided by the amount of money that the buyer must carry to buy the good, $0.05 / 0.95=5.2$ percent. The social return of

\section{FIGURE 5}

\section{WELFARE COST OF INFLATION UNDER PROPORTIONAL BARGAINING}
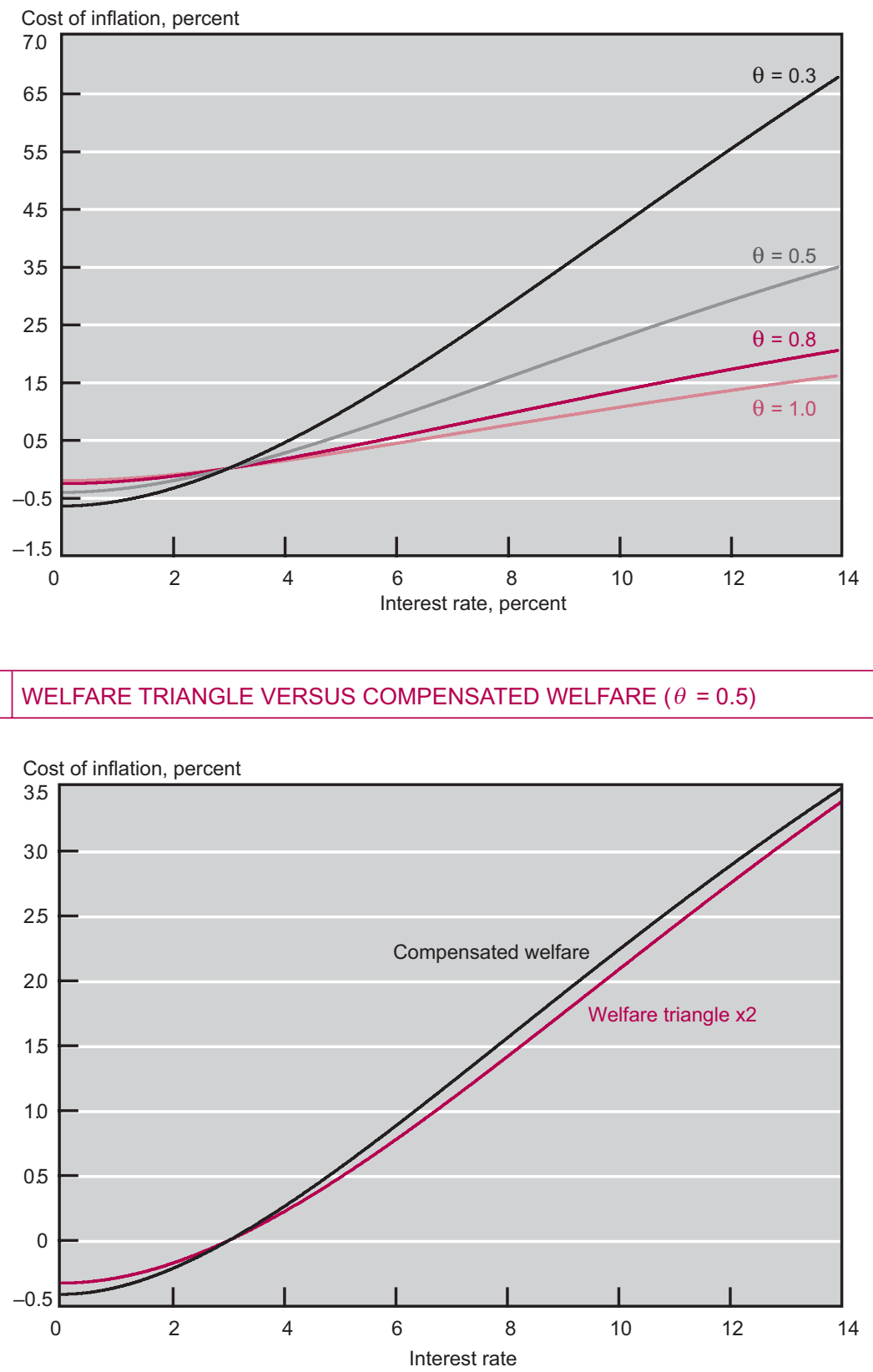
money is the total surplus divided by the price of the good, $0.1 / 0.95=10.5$ percent. If the interest rate is 10 percent, the cost of holding $\$ 0.95$ for the buyer is larger than the marginal gain of $\$ 0.05$. So the buyer has no incentive to bring an additional dollar even though the return of this dollar to society is larger than the opportunity cost incurred by the buyer.

This discrepancy between the private and social benefits of real balances arises from a rent-sharing externality. The marginal benefit of the real balances from the buyer's point of view is smaller than the marginal benefit from society's point of view. Since the money demand estimated from the data only captures the marginal benefit of money from the buyer's side, the welfare triangle misses a fraction of the welfare cost of inflation.This externality arises from any pricing rule that stipulates that the buyer does not get the full marginal return of his real balances. ${ }^{17}$

This point is illustrated in figure 7 . For a given stock of real balances $m_{0}$, the marginal benefit that money provides to the money holder, the length of segment $A B$, is smaller than the marginal societal benefit of money, the length of segment $A D$. If prices are determined according to a proportional solution, the ratio $B A / D A$ is the buyer's share. As a consequence, when measuring the area underneath the demand for real balances, the $A B C$ area, one underestimates the social benefit of money, the $A D C$ area, by a factor equal to the inverse of the buyer's share.

In figure 7 , the two curves representing the private and social benefits of real balances intersect the horizontal axis $(r=0)$ for the same value $m^{*}$ of real balances.At this point, the total benefits of real balances are maximized for both buyers and society. This observation implies that the Friedman rule yields the best allocation of resources for society for all values of the buyer's share, $\theta$.

The result in which the Friedman rule generates the first-best allocation does not hold for all bargaining solutions. For instance, it does not hold for the Nash (1950) solution, according to which $z(q)=\Theta(q) c(q)+[1-\Theta(q)] u(q)$ with

$$
\Theta(q)=\frac{\theta u^{\prime}(q)}{\theta u^{\prime}(q)+(1-\theta) c^{\prime}(q)}
$$

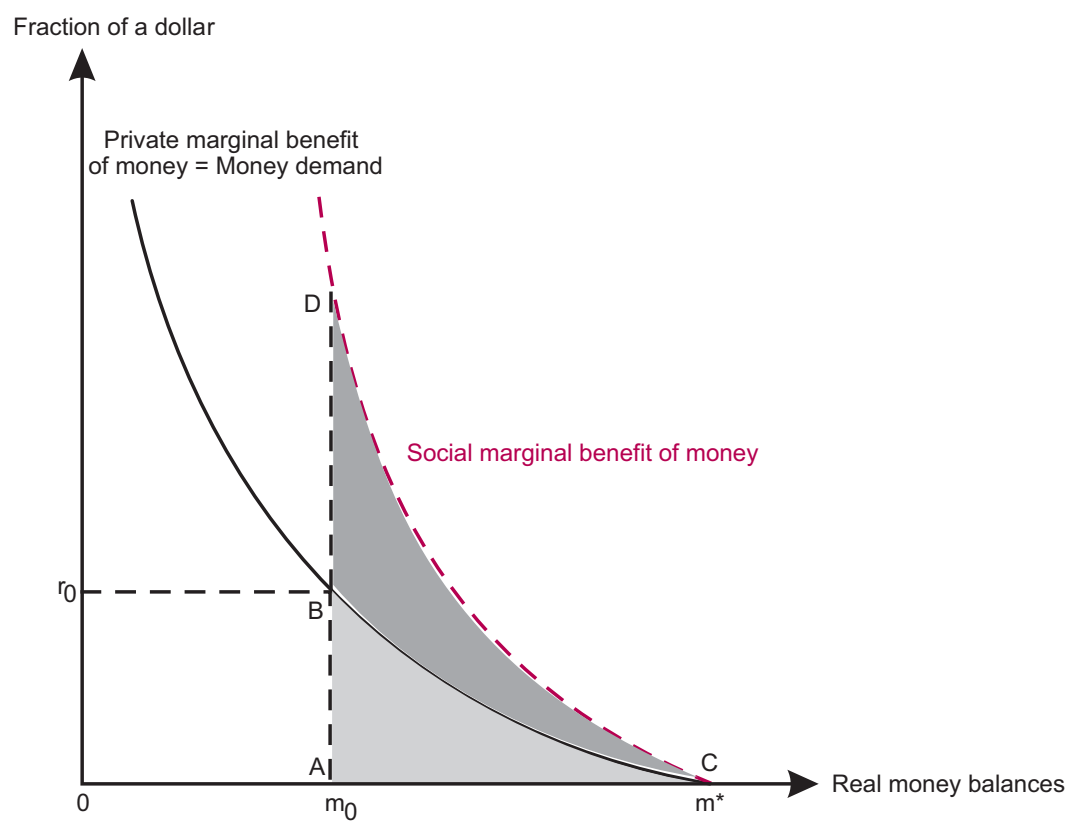


where $\theta$ is now the bargaining power of the buyer. ${ }^{18}$ The buyer's share, $\Theta$, depends on both $\theta$ and $q$, and it is equal to $\theta$ when $q=q^{*}$. In particular, the buyer's share, $\Theta$, decreases as $q$ increases.As shown by Lagos and Wright (2005), if prices in bilateral matches are determined according to the Nash solution, then the Friedman rule is optimal but the quantities traded in the decentralized market are too low. This result is illustrated in figure 8. At the Friedman rule $(r=0)$ the economy's real balances are $\tilde{m}$, while the real balances that would maximize society's welfare are $m^{*}$. In other words, if the interest rate is zero, an individual's demand for real balances is satiated even though the marginal benefit of money to society is still positive. This inefficiency is called a "nonmonotonicity inefficiency" to reflect the fact that the buyer's surplus from a trade does not necessarily increase with the match surplus. ${ }^{19}$ Put differently, the buyer's surplus $u(q)-z(q)$ reaches a maximum for a value of $q$ smaller than $q^{*}$. This inefficiency has two important consequences for the welfare effects of inflation. First, a small increase of the interest rate above $r=0$ will have a larger effect on welfare than in the case under proportional bargaining solutions. Indeed, the welfare cost of a small interest rate can be approximated by the change in real balances multiplied by the social benefit of real balances at $r=0$. This second term, measured by the length of the segment $E C$ in figure 8 , is now positive at $r=0$. Second, real balances are inefficiently low at $r=0$, and, as a consequence, the quantities produced and consumed in bilateral matches are also too low.

Figure 9 plots the welfare cost of inflation when prices are determined according to the Nash solution for different values of the buyer's bargaining power, $\theta$. The comparison of figures 5 and 9 reveals that the welfare cost of 10 percent inflation under the Nash solution is of same magnitude as the cost under the proportional bargaining solution. In both cases, there is a rent-sharing externality at work, which amplifies the cost of inflation. However, under the Nash solution, the buyer's share, $\Theta$, gets larger for higher inflation rates so that the rent-sharing externality gets smaller.The most noticeable difference between figures 5 and 9 is the gain associated with a reduction of the interest rate from 3 percent to zero (which corresponds to the optimal deflation rate). This gain can be as high as 2.5 percent of GDP when the buyer's bargaining power is 0.3 . Under the proportional solution, this

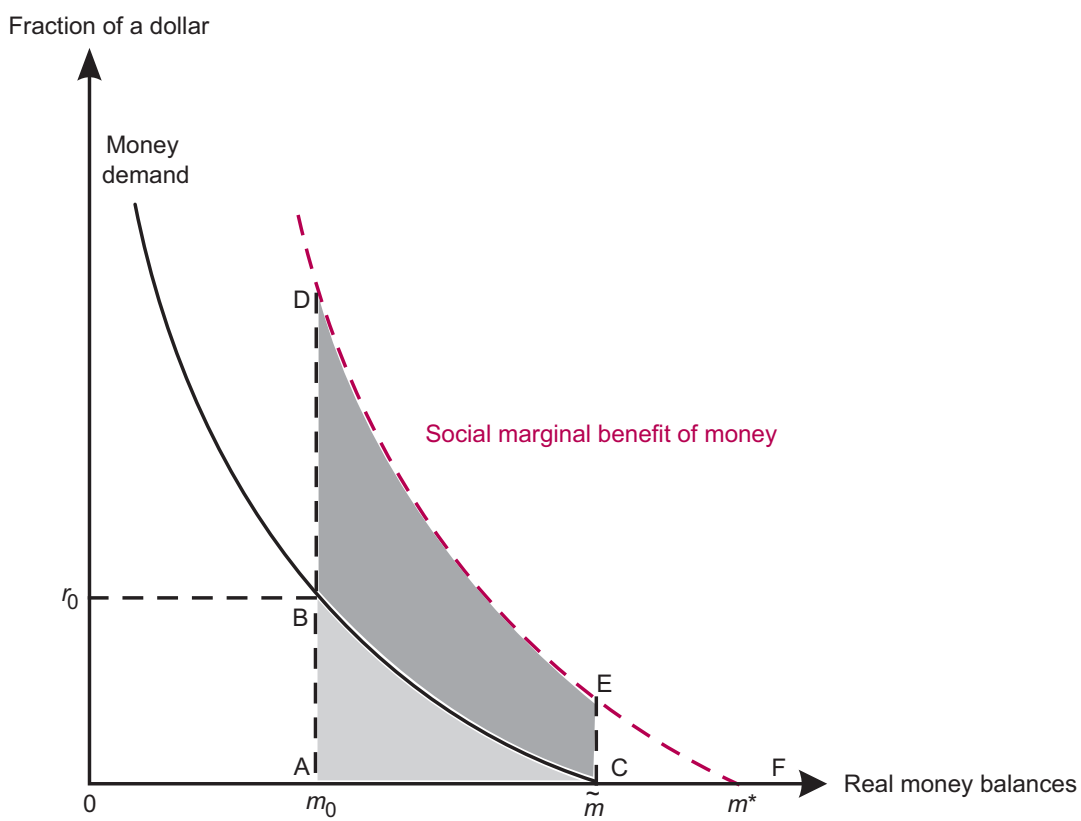

$m_{0}$
18. The bargaining power $\theta$, which varies from 0 to 1 , is a measure of the buyer's strength in the bargaining process. In an explicit bargaining game with offers and counteroffers, the bargaining power of an individual depends, among other things, on his ability to threaten to terminate the negotiation if his offer is rejected.

19. In order to illustrate this inefficiency, consider a bargaining problem where two individuals must share a prize. If one of the two individuals gets worse off as the size of the prize increases, then the bargaining solution is said to be nonmonotonic. For a detailed treatment of alternative bargaining solutions and their properties in monetary economies, see Rocheteau and Waller (2004). BARGAINING INEFFICIENCIES

FIGURE 8

0 
gain is about 0.5 percent of GDP. So the nonmonotonicity inefficiency is important in that it predicts large welfare gains if inflation is reduced from zero to the optimal deflation rate.

To conclude this section, we present a pricing mechanism which exhibits the same type of inefficiencies as the Nash bargaining solution but which is based on the possibly more familiar idea that prices are set as a markup over the cost incurred by sellers. ${ }^{20}$ More precisely, the transfer of money from the buyer to the seller corresponds to the cost incurred by the seller in producing the amount asked for by the buyer multiplied by a constant factor, $1+\mu$, (where $\mu \geq 0$ ), which we interpret as the "markup," $z(q)=(1+\mu) c(q)$. As shown in figure 10, the cost of inflation increases with the markup. When the markup is 20 percent, the cost of 10 percent inflation is slightly more than 3 percent of GDP, which is similar to the prediction of the model under the symmetric Nash solution.

\section{FIGURE 9}

\section{COST OF INFLATION UNDER NASH BARGAINING}
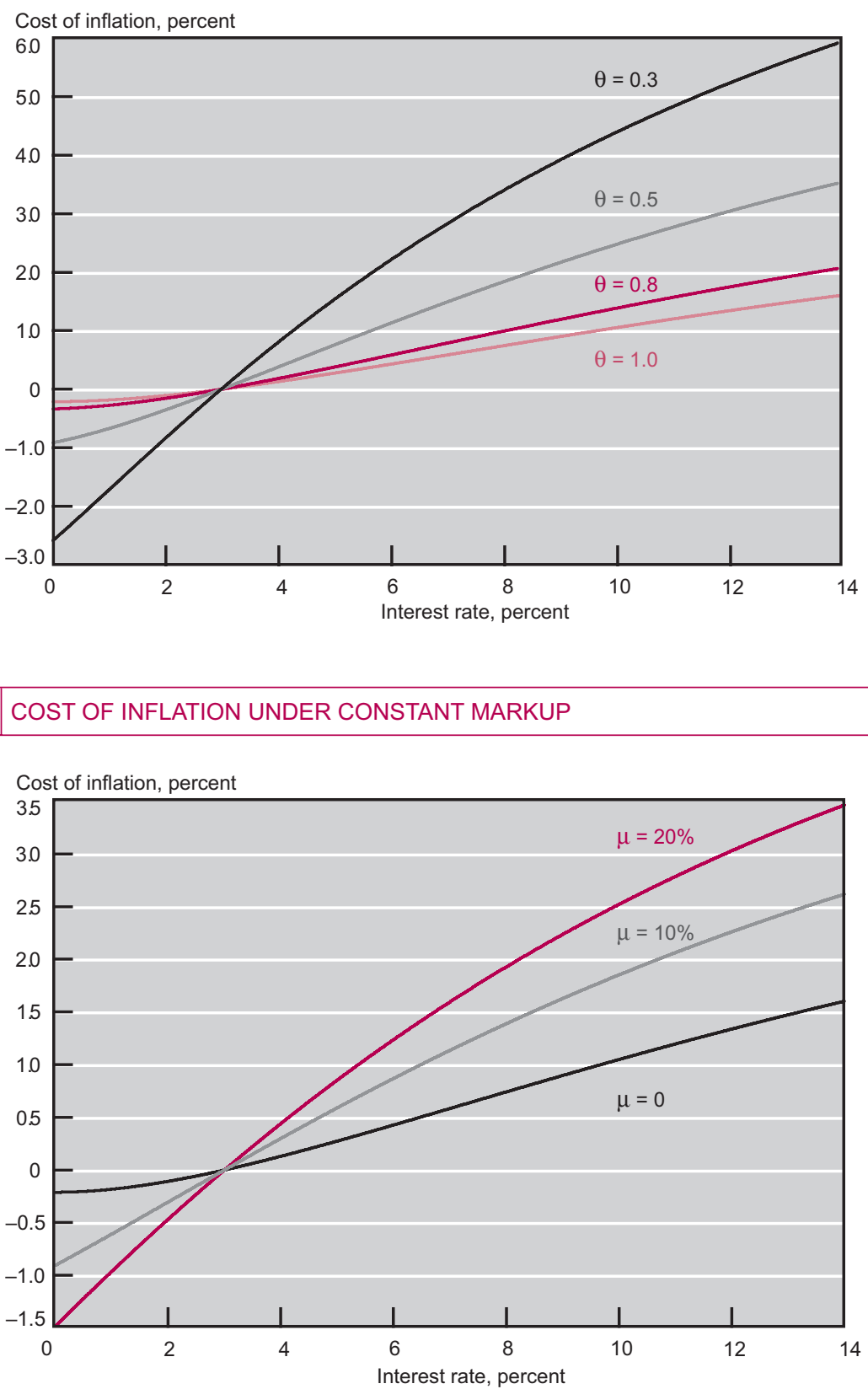

20. For a search model with price posting by sellers, see Ennis (2004). Ennis (2004) describes an economy in which buyers have private information about their tastes, and sellers make take-it-or-leave-it offers. The annual welfare cost of a 10 percent inflation in this model is between 4 percent and 7 percent of GDP. 
Figure 11 illustrates how a constant markup affects the assessment of the welfare cost of inflation. The constant markup, $\mu$, shifts the curve indicating the social return of real balances up by a constant amount $(B D=C E)$, which reflects the seller's marginal benefit from buyers' real balances. The larger the markup, the larger the difference between private and social benefits of real balances. Also, it is clear from figures 8 and 11 that both the Nash solution and the pricing with constant markup induce qualitatively similar effects of inflation. In both cases, the quantities traded at the Friedman rule $(r=0)$ are too low.

\section{Participation Decisions}

In the basic model described in the previous sections, the frequency of trade is assumed to be constant. So inflation affects the quantities traded in bilateral meetings, but it does not affect the number of those meetings. In order to endogenize the number of trade matches, one can let buyers and sellers choose whether or not to participate in the market, or let them choose on which side of the market to participate in, or even let them choose the resources they will invest in the search for a trading partner. ${ }^{21}$ By taking into account these participation decisions, one can introduce general equilibrium effects of inflation, which are not captured by the Bailey methodology. Also, in environments with search frictions, participation decisions tend to be inefficient. Consequently, the welfare effects of inflation are ambiguous and depend on the way in which inflation distorts participation decisions.

We consider in the following an extension of the Lagos-Wright model, which is based on an assumption in Shi (1997). ${ }^{22}$ The economy is similar to the one previously described except that at the beginning of each period, before matches are formed, individuals can choose to be buyers or sellers in the decentralized market. For instance, agents in the labor market can choose to be buyers (entrepreneurs) or sellers (workers).An agent who chooses to be a buyer cannot produce during the day, while an agent who chooses to be a seller cannot consume during the day. The composition of buyers and

21. Rocheteau and Wright (2005) consider a model with free entry of sellers. Shi (1997) describes an economy in which individuals can choose which side of the market to participate in. See also Rocheteau and Wright (2004) and Faig (2004). Li $(1995,1997)$ introduces endogenous search intensities.

22. Our model is similar to the one in Rocheteau and Wright (2004), except that we consider different pricing mechanisms. sellers is then endogenous. Let $n$ denote the fraction of sellers in the economy. Assume further that the matching process is such that a buyer meets a seller with probability $n$, whereas a seller meets a

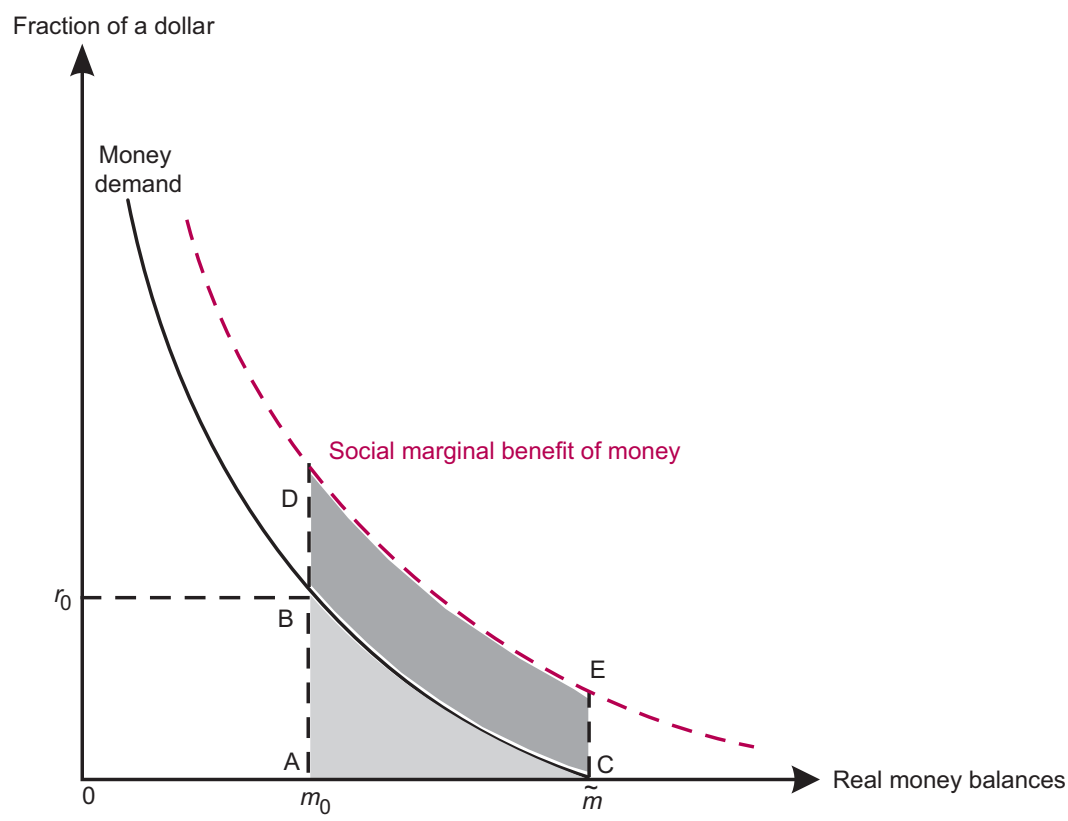


buyer with probability $1-n \cdot{ }^{23}$ The fraction of sellers in equilibrium is such that agents are indifferent to being buyers or sellers,

$-r z(q)+n[u(q)-z(q)]=(1-n)[z(q)-c(q)]$

The left-hand side of the previous equation is the expected utility of a buyer, the right-hand side is the expected utility of a seller, and $q$ is the equilibrium quantity traded in bilateral matches. ${ }^{24}$ We assume that prices are determined according to the proportional bargaining solution, $z(q)=\theta c(q)+(1-\theta) u(q)$.

The equilibrium allocation is socially efficient if $\theta=0.5$ and $r=0$. The second requirement corresponds to the Friedman rule, and it guarantees that $q=q^{*}$. The first requirement, $\theta=0.5$, is the condition under which the number of trades is maximized; this maximization requires $n=1 / 2$. It corresponds to the Hosios (1990) condition according to which the number of trades is efficient only in the unlikely event that an agent's share of the match surplus is equal to his marginal contribution to the creation of trade matches. ${ }^{25}$ The best outcome for a search monetary economy requires that both the Hosios condition and the Friedman rule hold. ${ }^{26}$

The definition of the aggregate demand for money is the money held by the $1-n$ buyers divided by the sum of the output in the decentralized market, $n(1-n) z$, and the output in the centralized market, $A$,

$$
L=\frac{(1-n) z}{n(1-n) z+A}
$$

We use the same strategy as before to estimate the parameters $A$ and $\eta$ of money demand. In figure 12, we report the welfare cost of inflation. When the buyer's share is less than 50 percent, the number of buyers is too low and inflation lowers the fraction of buyers even further.The welfare cost of low inflation is then larger than what would be obtained under the assumption in which the frequency of trades is constant. Reciprocally, the welfare gains from reducing the interest rate to zero are also large. When the buyer's share is above 50 percent, a deviation from the Friedman rule is optimal.

FIGURE 12 COST OF INFLATION WITH SEARCH EXTERNALITIES (PROPORTIONAL BARGAINING)

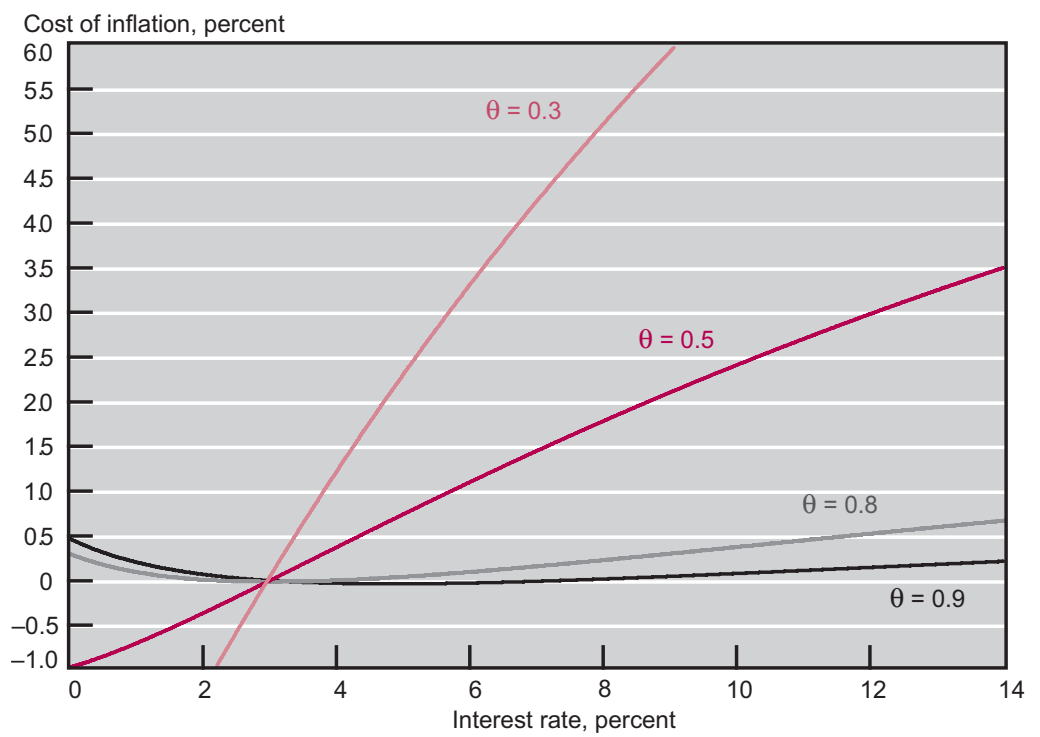

23. The specification for the matching function is the same as the one used in most monetary models, including Kiyotaki and Wright (1993). Obviously, it would be desirable to estimate the transaction technology. This strategy has been pursued successfully in the labor literature. We leave this extension for future investigation.

24. The money supply is growing through lump-sum transfers. Such transfers do not affect agents' decisions to be buyers or sellers.

25. The elasticity of the number of trades with respect to the number of buyers in the economy is $n$. Therefore, the Hosios condition requires $\theta=n$. When $r=0$, $n=1-\theta$, so that the optimal allocation requires $\theta=0.5$.

26. For an elaboration of this idea, see Berentsen, Rocheteau, and Shi (2004). 
In this case, if $r=0$, then the number of buyers is too high and the number of trades is too low. Since inflation has a direct negative effect on buyers' expected utility, the number of buyers falls, while the number of sellers increases. ${ }^{27}$ The composition in the market becomes more even and the number of trades increases. ${ }^{28}$ When the buyer's share is 90 percent, then the cost of implementing the Friedman rule is about 0.5 percent of GDP while the cost of 10 percent inflation is close to 0 .

The results reported in figure 12 have been derived by assuming that terms of trade are set according to a proportional bargaining solution.As in the previous section, different bargaining solutions can have very different properties in terms of the efficiency of the equilibrium allocation at the Friedman rule. For example, in the basic Lagos-Wright model, the equilibrium allocation is efficient at the Friedman rule under the proportional bargaining solution, but it is inefficient under the Nash solution. Not too surprisingly, the choice of the pricing mechanism will also matter considerably for the welfare cost of inflation when participation decisions are endogenous.

Figure 13 reports the cost of inflation when the terms of trade are determined according to the Nash solution. In sharp contrast to the results obtained under the proportional solution, there is no positive effect of inflation on welfare. The optimal monetary policy is the Friedman rule. The "nonmonotonicity inefficiency" of the Nash solution changes the nature of the trade-off between the negative effect of inflation on individual real balances and the effect of inflation on the composition of the market. Indeed, since real balances are inefficiently low at the Friedman rule under the Nash solution, a small increase of the interest rate reduces real balances, which has a first-order negative effect on welfare. For the calibrated version of the model, this negative real balance effect dominates any positive effect of inflation on the composition of the market. ${ }^{29}$ As a consequence, a deviation from the Friedman rule is not optimal under the Nash solution. The comparison of figures 9 and 13 reveals that the presence of search externalities exacerbates the cost of inflation for large values of the buyer's bargaining power. If the buyer's bargaining power is 0.5 , results are largely similar to those obtained in the absence of search externalities, because at this value of $\theta$, the composition of the market is similar to the market in which $\sigma=1 / 2$. If the buyer's bargaining power is 0.9 , the cost of 10 percent inflation is about 4.5 percent of GDP in the presence of search frictions, whereas it is less

\section{FIGURE $13 \quad$ COST OF INFLATION WITH SEARCH EXTERNALITIES (NASH BARGAINING)}

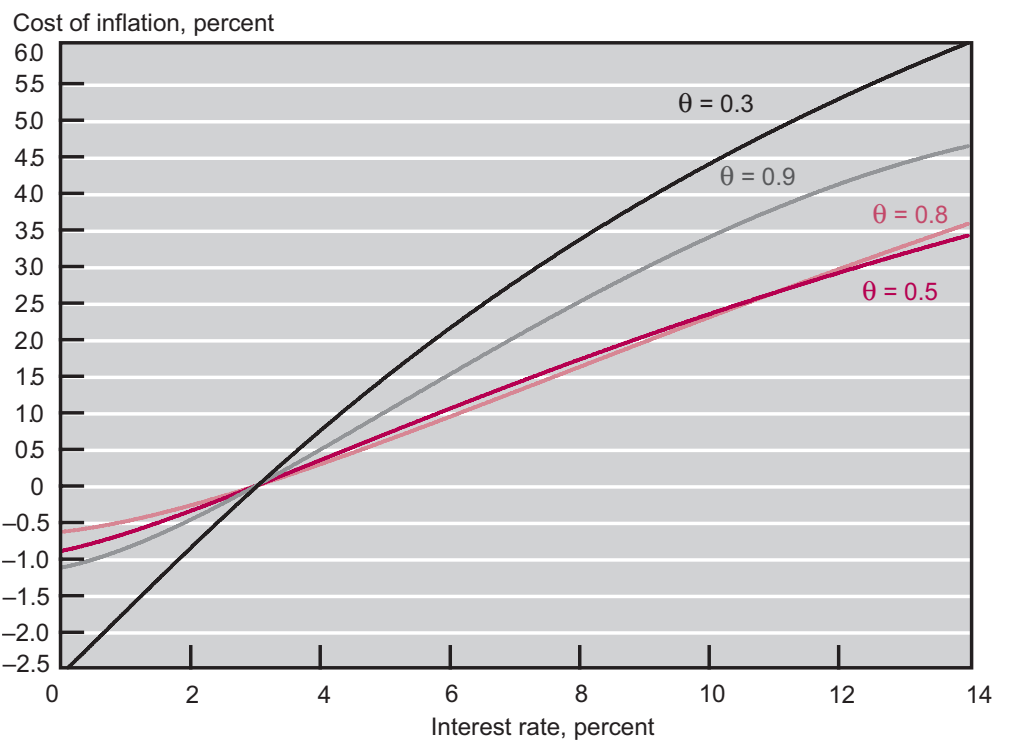

27. This effect is sensitive to the choice of the pricing mechanism. For instance, under the Nash solution the number of buyers can increase with inflation because the buyer's share in the surplus of a match gets bigger.

28. The result in which the Friedman rule is not always optimal in the presence of search externalities could raise the following objection. If the government was able to make transfers contingent on agents' participation decisions, then it could take care of the search externalities by an appropriate transfer scheme, while the Friedman rule would be used to reduce the monetary wedge associated with the inflation tax. In practice, however, it may be difficult to implement transfers contingent on agents' participation decisions since these decisions may not be observable. Inflation, which is a tax on market activities, may be an effective instrument for correcting inefficient participation in the market.

29. For other parameterizations, a deviation from the Friedman rule could raise society's welfare. However, the result according to which a deviation from the Friedman rule is less likely under Nash bargaining than under proportional bargaining is robust. 
than 2 percent of GDP when the frequency of trades is exogenous.Also, the welfare cost of inflation is not a monotonic function of the buyer's bargaining power. An increase in the buyer's bargaining power makes the rent-sharing externality less severe, but it also distorts the composition of the market toward too many buyers.

To summarize, the introduction of endogenous participation decisions has several implications. First, the welfare triangle is a misleading measure since it does not capture the distortionary effects of inflation on individuals' participation decisions. Second, the presence of search externalities can mitigate or exacerbate the welfare cost of inflation.Third, the Friedman rule may no longer be optimal, as the positive effect of inflation on the composition of the market and the frequency of trades can dominate the negative effect of inflation on real balances.

\section{Distributional Effects}

The Lagos-Wright model described in the previous sections has been designed in such a way that all agents, despite different trading histories in the decentralized market, start each period with the same money balances. This property of the model is what makes it tractable. However, because the distribution of money balances is degenerate, inflation does not have any distributional effect. Levine (1991), Molico (1999), and Deviatov and Wallace (2001), among others, have provided examples in which a policy that consists of increasing the money supply through lump-sum transfers induces some redistribution across individuals. For individuals with large stocks of nominal assets, the burden associated with the inflation tax is greater than the benefit of receiving a lump-sum transfer. On the other hand, individuals with few nominal assets enjoy a net benefit from the lump-sum transfer. In some circumstances this redistribution can be beneficial to society. For example, if agents are subject to idiosyncratic shocks (on endowments, productivity, and so forth) that cannot be insured against, money growth can provide an insurance mechanism. ${ }^{30}$

We capture the distributional effects of inflation through a simple extension of the Lagos-Wright model. Recall that in the Lagos-Wright model individuals live forever, and, in each period of their lives, they trade sequentially in a centralized market and a decentralized market. We depart from these assumptions by assuming that individuals live only two periods. They are born at the beginning of the centralized market, and they die at the end of the following period after the centralized market has closed.Also, agents do not discount utility across periods. When agents are born, they have access to the centralized market in order to make their choice of money balances. In the second period of their lives, they trade in the decentralized market and then have access to the centralized market before they die. Only a fraction $p$ of the newly-born agents are able to produce in the first period of their lives. One can interpret this assumption as individuals receiving productivity shocks. In the absence of money growth, agents who cannot produce cannot accumulate money and, therefore, cannot consume in the decentralized market in the second period of their lives. By inflating the money supply the government can transfer money to all individuals, irrespective of their productivities, and therefore smooth consumption across all agents.

The demand for real balances from productive agents is the same as the one described in the previous sections. The main difference with respect to the previous models is the fact that the distribution of real balances has two points, $z$, the real balances of productive agents, and $\tilde{z}$, the real balances of unproductive agents. The aggregate demand for money balances is then
30. In Molico's (1999) version of the search-theoretic model, individuals trade only in a decentralized market with bilateral random matching. Since the matching process is random, trading opportunities arrive according to a stochastic process. Some individuals are lucky and can sell their output often: They then have a large stock of money balances. Other individuals are less lucky and have a low stock of real balances. Molico shows that for low inflation rates the redistributive effect of inflation, according to which inflation acts as a subsidy for the poor and a tax on the rich, can dominate the real balance effect of inflation, according to which inflation reduces aggregate real balances. In Craig and Waller's (2004) version of a decentralized market with two currencies, one of which inflates, low rates of inflation can induce a strong redistributive effect in the inflating currency where buyers are likely to hold either large amounts of the currency or none at all. 


$$
L=\frac{p z+(1-p) \tilde{z}}{\sigma[p z+(1-p) \tilde{z}]+A}
$$

The strategy to estimate the model is the same as before. Society's welfare is measured by the sum of the trade surpluses in all matches. The welfare cost corresponding to an interest rate, $r$, is the fraction by which total consumption at the steady state with a 3 percent interest rate must be reduced in order to achieve the same welfare as the one that prevails at the steady state with $r .{ }^{31}$ In figure 14 , we plot the welfare cost of inflation when prices are determined according to the proportional bargaining solution with $\theta=1 / 2$. As in Molico (1999), society's welfare is maximized for a positive inflation rate. The welfare gains associated with a positive interest rate are rather small. When calibrating the

31. Note that we kept the benchmark for the interest rate at 3 percent. Since agents do not discount future utility, this interest rate corresponds to a 3 percent inflation.

\section{\begin{tabular}{l|l} 
FIGURE 14 & DISTRIBUTIONAL EFFECTS OF INFLATION
\end{tabular}}

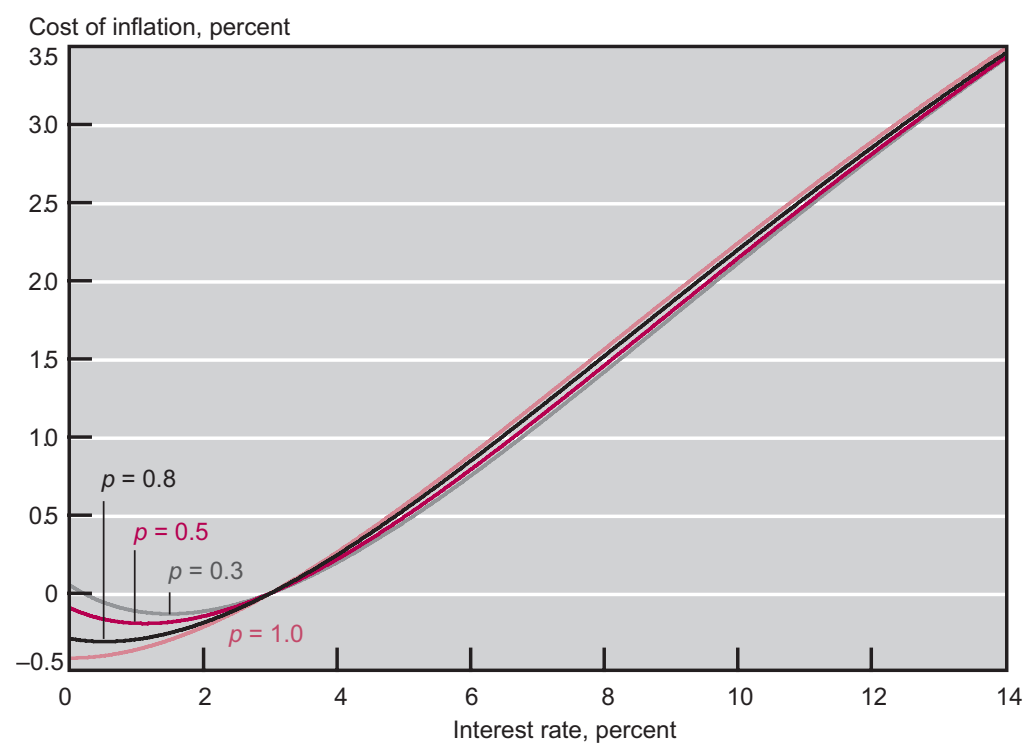

\begin{tabular}{l|l} 
FIGURE 15 & DISTRIBUTIONAL EFFECTS OF INFLATION (HIGHER RISK AVERSION)
\end{tabular}

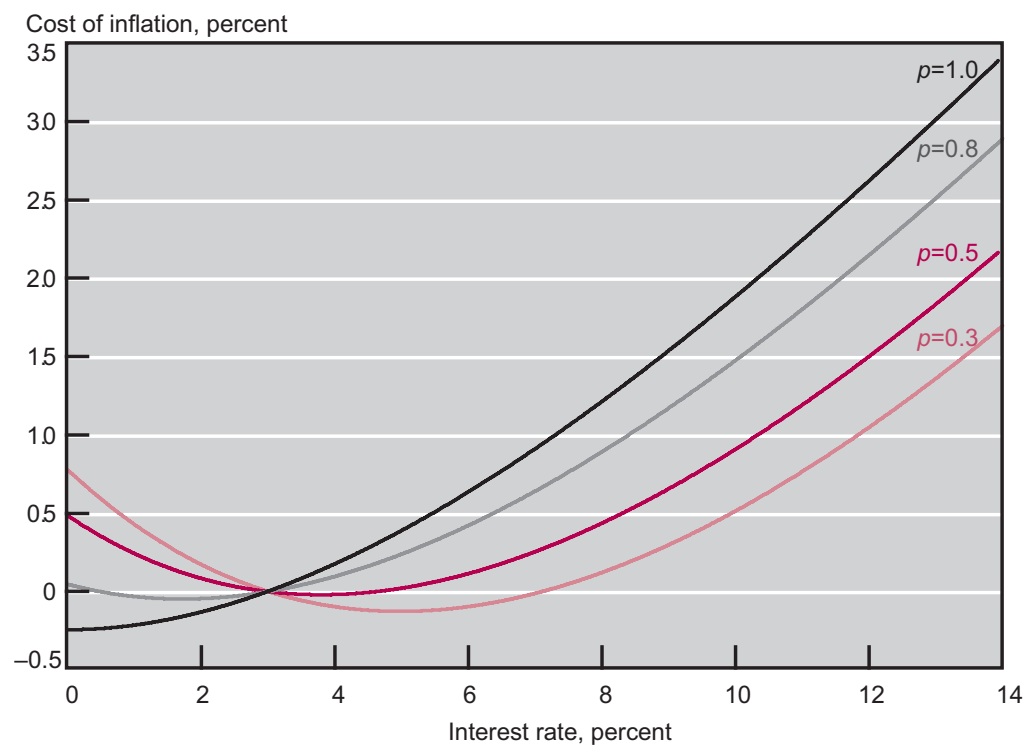


model, the coefficient that describes the aversion of individuals toward risk is low (the coefficient of relative risk aversion is close to 0.2 ), and it is, in fact, lower than what is usually thought realistic.

If one increases this coefficient to make it a little bit more realistic, the welfare gain corresponding to the redistribution effect of inflation gets larger. For example, in figure 15 we plot the cost of inflation for the same value of the parameter $A$ as the one used to draw figure 14 but for a coefficient of relative risk aversion raised to 0.5 . The benefits of inflation get significantly bigger and increase with the probability that an agent receives a negative productivity shock.

\section{Conclusion}

We have presented some insights provided by the search theory of monetary exchange for the understanding of the welfare cost of inflation. Using different extensions of the model of Lagos and Wright (2005), we have identified and quantified various effects of inflation on welfare. First, inflation has a negative real balance effect. The inflation tax introduces a wedge in the decision to invest in real balances. The extent of this distortion depends crucially on the assumed pricing mechanism. If buyers receive the full marginal benefit of their money balances, the cost of inflation is essentially the Bailey measure, given by the area underneath the money demand function. In all other cases, the Bailey measure has to be scaled up by a function that depends on the sellers' share in the surplus of a trade. We have also provided examples of pricing mechanisms under which the Friedman rule fails to generate the first-best allocation. In such cases, the benefit of implementing the optimal deflation is large. Second, inflation affects agents' decisions to participate in the market and therefore it affects the number of trades. However, since participation decisions tend to be inefficient in search environments, the effect of inflation on participation choices can be welfare-enhancing or welfare-worsening. We have provided calibrated examples in which a deviation from the Friedman rule is optimal. We have shown once again that the welfare effects of inflation depend crucially on the pricing mechanism. Third, inflation can generate a redistribution across agents. If agents are subject to idiosyncratic shocks, this redistribution can prove useful to society.

Additional extensions would be worth considering. As emphasized by Cooley and Hansen (1989, 1991) and Dotsey and Ireland (1996), the inflation tax can distort a variety of marginal decisions: among others, the leisure-consumption choice and the accumulation of capital.Aruoba and Wright (2003) and Aruoba, Waller, and Wright (2004) have extended the Lagos-Wright model to allow for capital accumulation and have considered various assumptions regarding how capital enters the economy.Also, as Kocherlakota (2004) pointed out, it is important to extend search models in order to incorporate additional assets beside money, such as government bonds, and to take into account distortionary taxes. Finally, one can introduce realistic nominal rigidities in the search model of money along the lines suggested by Craig and Rocheteau (2004). 


\section{Appendix 1:The Model}

\section{The Lagos-Wright Model of Monetary Exchange}

We present briefly the search-theoretic model of monetary exchange proposed by Lagos and Wright (2005). Time is discrete and each period of time is divided into two subperiods: the day and night. During the day trades take place in a decentralized market where agents are matched bilaterally. There is a lack of double coincidence of wants in bilateral matches. The probability for an agent to find someone who produces a good he likes is $\sigma$, and the probability to find someone who likes the good he produces is $\sigma$. With probability $1-2 \sigma$ an agent is unmatched. Night trades take place in a competitive market. Money is introduced in the economy through lump-sum transfers in the centralized market and the supply of money is growing at the rate $\pi$. We only focus on steady-state equilibria where real balances are constant.

An agent's utility function is

$u\left(q^{b}\right)-c\left(q^{s}\right)+x$

where $q^{b}$ is the consumption and $q^{s}$ the production in a bilateral match and $x$ is the net consumption in the centralized market ( $x$ is negative if an agent produces more at night than he consumes). When we calibrate the money demand function we assume $u(q)=q^{1-\eta} /(1-\eta)$, where $\eta \in(0,1)$ and $c(q)=q$. The discount factor is $\beta=(1+\rho)^{-1} \in(0,1)$.

Let $p_{t}$ denote the price in the centralized market.The utility of an agent holding $m_{t}$ units of money during the night of period $t$, denoted by $W\left(m_{t} / p_{t}\right)$, satisfies

$$
\begin{gathered}
W\left(\frac{m_{t}}{p_{t}}\right)=\max _{x_{t} \hat{m}_{t+1}}\left\{x_{t}+\beta V\left(\frac{\hat{m}_{t+1}}{p_{t+1}}\right)\right\}, \\
\text { s.t. } p_{t} x_{t}+\hat{m}_{t+1}=m_{t}+T_{t}
\end{gathered}
$$

where $V(\cdot)$ is the expected utility of the individual in the decentralized market.

The individual receives a lump-sum transfer $T_{t}$ and chooses his net consumption $x_{t}$ and his money balances $\hat{m}_{t+1}$ in the next period. It is straightforward to check that the value function is linear and that the choice of $\hat{m}_{t+1}$ is independent of $m_{t}$. Note that the absolute value of consumption and production in the centralized market is not determined within the model. The aggregate production in the centralized market will be determined by calibration.

Terms of trade $(q, d)$ in a bilateral match, where $q$ is the output and $d$ the real transfer of money, are determined by a bargaining solution. In general, the terms of trade maximize a monotonic function of the surpluses of the buyer and the seller in the match. Those surpluses are independent of the money balances of the buyer and the seller.Also, for standard bargaining solutions, $(q, d)$ only depends on the real balances $z_{t}=m_{t} / p_{t}$ of the buyer.

The utility of an agent in the decentralized market satisfies

$$
V\left(\frac{m_{t}}{p_{t}}\right)=\sigma\left[u\left(q^{b}\right)+W\left(\frac{m_{t}}{p_{t}}-d^{b}\right)\right]+\sigma\left[-c\left(q^{s}\right)+W\left(\frac{m_{t}}{p_{t}}-d^{s}\right)\right]+(1-2 \sigma) W\left(\frac{m_{t}}{p_{t}}\right)
$$


where $\left(q^{b}, d^{b}\right)$ are the terms of trade when the agent is the buyer and $\left(q^{s}, d^{s}\right)$ are the terms of trade when the agent is the seller. In equilibrium, $\left(q^{b}, d^{b}\right)=\left(q^{s}, d^{s}\right)$ since all agents hold the same money balances. Substitute $V\left(m_{t} / p_{t}\right)$ into the Bellman equation for $W\left(m_{t} / p_{t}\right)$ and rearrange in order to obtain the following problem

$$
\max _{q_{t}}\left\{-r_{t} z\left(q_{t}\right)+\sigma\left[u\left(q_{t}\right)-z\left(q_{t}\right)\right]\right\}
$$

where the nominal interest rate $r_{t}$ satisfies $1+r_{t}=(1+\pi)(1+\rho)$ and where $z(q)$ relates the buyer's real balances to the quantity of goods he can purchase from the seller. So the agent essentially maximizes the expected surplus he gets when he is a buyer minus the cost of holding real balances.

\section{Pricing Mechanisms}

The form of the function $z(q)$ depends on the bargaining solution. If buyers have all the bargaining power, then $z(q)=c(q)$ and the first-order condition is

$\frac{u^{\prime}(q)}{c^{\prime}(q)}=1+\frac{r}{\sigma}$

Using the specifications for the utility and cost functions, this gives

$q=z=\left(1+\frac{r}{\sigma}\right)^{\frac{-1}{\eta}}$

If terms of trade are determined according to the proportional bargaining solution, then the relationship between individual balances and the quantity traded in a match is given by $z(q)=\theta c(q)+(1-\theta) u(q)$, where $\theta$ is the buyer's share in the match surplus. Using the linear specification for $c(q)$ and the CRRA specification for $u(q)$, and the first-order condition for the choice of real balances, one obtains

$$
z=\left(\frac{1-\theta}{1-\eta}\right)\left(\frac{(r+\sigma) \theta}{\sigma \theta-r(1-\theta)}\right)^{\frac{-(1-\eta)}{\eta}}+\theta\left(\frac{(r+\sigma) \theta}{\sigma \theta-r(1-\theta)}\right)^{\frac{-1}{\eta}}
$$

If terms of trade are determined according to the generalized Nash bargaining solution where the buyer's bargaining power is $\theta$, the pair $(z, q)$ satisfies

$$
\begin{aligned}
z(q) & =\frac{\theta u^{\prime}(q) c(q)+(1-\theta) c^{\prime}(q) u(q)}{\theta u^{\prime}(q)+(1-\theta) c^{\prime}(q)} \\
\frac{u^{\prime}(q)}{z^{\prime}(q)} & =1+\frac{r}{\sigma} .
\end{aligned}
$$

Finally, if prices are set as a constant markup over the cost incurred by sellers, the function $z(q)$ satisfies

$z(q)=(1+\mu) c(q)$ 


\section{Calibration}

The money demand function that is confronted with the data is defined as aggregate money balances divided by aggregate nominal output. It is equal to

$\frac{M}{\sigma M+p A}$

where $M$ is aggregate money balances, $\sigma$ is the frequency of trades in the decentralized market, $p$ is the price in the centralized market, and $A$ is the real output in the centralized market. Since $z=$ $M / p$, the money demand function is

$\frac{z}{\sigma z+A}$

If the pricing mechanism is "buyers take all" then the expression for money demand is

$$
\frac{z}{\sigma Z+A}=\frac{1}{\sigma+A\left(1+\frac{r}{\sigma}\right)^{\frac{1}{\eta}}}
$$

The frequency of trades is set to $\sigma=0.5$ so that each individual is matched and is either a buyer or a seller.The parameters $A$ and $\eta$ are chosen to fit money demand in the United States over the period 1900-2000.The same procedure is used for other pricing mechanisms.

\section{Social and Private Marginal Returns of Real Balances}

A marginal unit of real balances allows a buyer to buy $\partial q / \partial z$ units of goods in the event a match occurs. The expected private marginal return of real balances, or equivalently, the expected increase of the buyer's utility from holding an additional unit of real balances, is then $\sigma\left[u^{\prime}(q)-z^{\prime}(q)\right] \partial q / \partial z=\sigma\left[u^{\prime}(q) / z^{\prime}(q)-1\right]$, which is precisely $r$ from the first-order condition for the choice of real balances. The expected social marginal return of real balances is $\sigma\left[u^{\prime}(q)-c^{\prime}(q)\right] \partial q / \partial z=\sigma\left[u^{\prime}(q)-c^{\prime}(q)\right] / z^{\prime}(q)$. Note that the private and social returns of real balances are equal when buyers have all the bargaining power since $z(q)=c(q)$. If prices are determined by the proportional bargaining solution then the social return of real balances is

$$
\sigma\left[\frac{u^{\prime}(q)-c^{\prime}(q)}{z^{\prime}(q)}\right]=\frac{\sigma}{\theta}\left[\frac{u^{\prime}(q)-z^{\prime}(q)}{z^{\prime}(q)}\right]=\frac{r}{\theta} .
$$

So the social return of real balances is equal to the interest rate divided by the buyer's bargaining power. Finally, if prices are determined according to a constant markup $\mu$ over the cost incurred by the seller then the social return of real balances is

$$
\sigma\left[\frac{u^{\prime}(q)-c^{\prime}(q)}{z^{\prime}(q)}\right]=\sigma\left[\frac{u^{\prime}(q)-z^{\prime}(q) /(1+\mu)}{z^{\prime}(q)}\right]=r+\sigma \frac{\mu}{1+\mu}
$$

So the social return of real balances is equal to the interest rate plus a constant term that is increasing in $\mu$. 


\section{Accurateness of the Welfare Triangle Measure}

The inverse money demand function of the search model is given by

$r=\sigma\left\{u^{\prime}[q(x)] q^{\prime}(x)-1\right\}$

where $q(x)$ is the function that specifies the output traded in bilateral matches as a function of real balances. Denote $z_{0}\left(z_{r}\right)$ the real balances at the steady-state equilibrium with an interest rate of 3 percent ( $r$ percent). Integrate the inverse money demand function from $z_{r}$ to $z_{0}$ in order to obtain the welfare triangle measure (denoted WT),

$$
\begin{aligned}
W T & =\int_{z_{r}}^{z_{0}} \sigma\left\{u^{\prime}[q(x)] q^{\prime}(x)-1\right\} d x \\
& =\sigma\left\{u\left[q\left(z_{0}\right)\right]-z_{0}\right\}-\sigma\left\{u\left[q\left(z_{r}\right)\right]-z_{r}\right\} .
\end{aligned}
$$

When buyers make take-it-or-leave-it offers,

$W T=\sigma\left\{u\left[q\left(z_{0}\right)\right]-c\left[q\left(z_{0}\right)\right]\right\}-\sigma\left\{u\left[q\left(z_{r}\right)\right]-c\left[q\left(z_{r}\right)\right]\right\}$

In this case, he welfare triangle coincides exactly with the change in society's welfare. When prices are determined according to the proportional bargaining solution,

$W T=\sigma \theta\left\{u\left[q\left(z_{0}\right)\right]-c\left[q\left(z_{0}\right)\right]\right\}-\sigma \theta\left\{u\left[q\left(z_{r}\right)\right]-c\left[q\left(z_{r}\right)\right]\right\}$

Now the welfare triangle measure is equal to the buyer's share times the change in society's welfare.

\section{Measuring the Welfare Cost of Inflation}

Consider two steady states, one associated with an interest rate of 3 percent (the nominal interest rate that is consistent with 0 inflation) and one associated with an interest $r$. The welfare cost of an interest rate $r$ is measured by the rate $\Delta$, at which consumption in the steady state with an interest rate of 3 percent must be decreased to make agents indifferent between this steady state and the steady state with a nominal interest rate $r$. Let $q_{r}$ denote the quantities traded in a steady state when the interest rate is $r$. The cost of inflation $\Delta$ solves

$\sigma\left\{u\left[q_{0.03}(1-\Delta)\right]-c\left(q_{0.03}\right)\right\}-A \Delta=\sigma\left[u\left(q_{r}\right)-c\left(q_{r}\right)\right]$.

Using the functional forms for $u(q)$ and $c(q)$ this gives

$$
\frac{\left(q_{0.03}\right)^{1-\eta}}{1-\eta}(1-\Delta)^{1-\eta}-\frac{A}{\sigma} \Delta=\frac{\left(q_{r}\right)^{1-\eta}}{1-\eta}+q_{0.03}-q_{r} .
$$

\section{Endogenous Composition of Buyers and Sellers}

We introduce an assumption used by Shi (1997), and subsequently by Rocheteau and Wright (2004), Rocheteau and Waller (2005) and Faig (2004), to endogenize the frequency of trades. In the LagosWright model, each individual can be a buyer or a seller in the decentralized market depending on whom he meets. The frequency of trades is then given by an exogenous matching probability $\sigma$. We 
now allow each agent to choose on which side of the market to participate in: Each agent can choose to be a buyer or a seller in the decentralized market. Let $n$ denote the fraction of sellers. The matching technology is such that a buyer meets a seller with probability $n$ and a seller meets a buyer with probability $1-n$. So the aggregate number of trades is $n(1-n)$ and it is maximum when the composition of the market is symmetric, $n=1-n=1 / 2$. The number of sellers in equilibrium is such that an agent is indifferent between being a buyer or a seller. Consequently, $n$ satisfies

$-r z(q)+n[u(q)-z(q)]=(1-n)[z(q)-c(q)]$

where $z(q)$ is the buyer's real balances as a function of $q$. (The growth of money supply occurs through lump-sum transfers. These transfers do not affect agents' decisions to be buyers or sellers.) The right hand-side is the expected surplus of a buyer in the decentralized market net of the cost of holding real balances. The right hand-side is the expected utility of a seller in the decentralized market.The previous equation can be solved for $n$,

$n=\frac{(1+r) z(q)-c(q)}{u(q)-c(q)}$

The form taken by $z(q)$ depends on the pricing mechanism that is assumed. If prices are determined by the proportional bargaining solution then

$z(q)=\theta c(q)+(1-\theta) u(q)$

The choice of real balances satisfies an equation similar to the one in the basic Lagos-Wright model, that is,

$\frac{u^{\prime}(q)}{z^{\prime}(q)}=1+\frac{r}{n}$

Substituting $n$ by its expression as a function of $q$ gives

$\frac{u^{\prime}(q)}{z^{\prime}(q)}=1+\frac{r[u(q)-c(q)]}{(1+r) z(q)-c(q)}$.

The aggregate money demand function that is fitted to the data is

$\frac{(1-n) z}{n(1-n) z+A}$

where both $n$ and $z$ are functions of the interest rate $r$. Since the number of trades is $n(1-n)$, steadystate welfare is measured by $n(1-n)[u(q)-c(q)]$. The welfare cost of inflation is the value $\Delta$ that solves

$n_{0.03}\left(1-n_{0.03}\right)\left\{u\left[q_{0.03}(1-\Delta)\right]-c\left(q_{0.03}\right)\right\}-A \Delta=n_{r}\left(1-n_{r}\right)\left[u\left(q_{r}\right)-c\left(q_{r}\right)\right]$

where $n_{r}$ and $q_{r}$ are the values for $n$ and $q$ at the steady state corresponding to the interest rate $r$. 


\section{Distributional Effects of Monetary Policy}

We now consider a variant of the Lagos-Wright model where individuals only live for three periods.All agents are born at the beginning of night before the centralized market opens, and they die at the end of the subsequent period after the centralized market closes. So agents can trade in the first period of their life in the centralized market and in the second period of their life in both the decentralized market and the centralized market. For simplicity, we assume that agents do not discount future utility, $\rho=0$, so that $r=\pi$.In the second period of their lives, agents are identical to the agents in the LagosWright model. In order to introduce distributional effects of monetary policy we add the following assumption. Only a fraction $p$ of the newly-born agents are able to produce in the first period of their lives. The remaining $1-p$ cannot produce and therefore cannot obtain money balances except from lump-sum transfers by the government. If $p=1$ the model is analogous to the Lagos-Wright model. The choice $q$ (the quantity consumed in the decentralized market) by newly-born agents satisfies

$$
\max _{q}\{-r z(q)+\sigma[u(q)-z(q)]\}
$$

$q$

where $z(q)$ is given by the bargaining solution. Let $T_{t}$ denote the lump-sum transfer at night in period $t$. By definition $T_{t}=M_{t+1}-M_{t}=\pi M_{t}$, where $M_{t}$ is the quantity of money in the decentralized market in period $t$. Let $m_{t}$ denote the nominal money balances held by agents who can produce.Agents who cannot produce hold $T_{t-1}$. Then, $p m_{t}+(1-p) T_{t-1}=M_{t}$ and

$T_{t-1}=\frac{p \pi}{1+p \pi} m_{t}$

Let $q_{t}\left(\tilde{q}_{t}\right)$ denote the quantity consumed in the decentralized market by those agents who can (cannot) produce in the first period of their lives. Since $z\left(\tilde{q}_{t}\right)=T_{t-1} / p_{t}$ and $z\left(q_{t}\right)=m_{t} / p_{t}$ then

$z(\tilde{q})=\frac{p \pi}{1+p \pi} z(q)$

If $\pi=0$, then $\tilde{q}=0$; and if $\pi=\infty$, then $q=\tilde{q}$. The aggregate money demand function that has to be fitted to the data is

$$
\frac{p z(q)+(1-p) z(\tilde{q})}{\sigma[p z(q)+(1-p) z(\tilde{q})]+A}=\frac{z(q)}{\sigma z(q)+\frac{(1+p \pi)}{p(1+\pi)} A}
$$

Social welfare is measured simply by the sum of utilities across agents, that is,

$\sigma p[u(q)-c(q)]+\sigma(1-p)[u(\tilde{q})-c(\tilde{q})]$.

The welfare cost of inflation is measured by $\Delta$ that solves

$\sigma p\left\{u\left[q_{0.03}(1-\Delta)\right]-c\left(q_{0.03}\right)\right\}+\sigma(1-p)\left\{u\left[\tilde{q}_{0.03}(1-\Delta)\right]-c\left(\tilde{q}_{0.03}\right)\right\}-A \Delta$

$=\sigma p\left[u\left(q_{r}\right)-c\left(q_{r}\right)\right]+\sigma(1-p)\left[u\left(\tilde{q}_{r}\right)-c\left(\tilde{q}_{r}\right)\right]$. 


\section{Appendix 2: Data Description}

The interest rate is the short-term commercial paper rate. From 1900 to 1975, it is taken from Friedman and Schwartz (1982), Table 4.8, Column 6. From 1976 to 1994, it is from the Economic Report of the President (1996), Table B-69. From 1995 to 1997, it is from Economic Report of the President (2003), Table B-73. From 1998 to 2000 it is the short-term 90-day AA credit rate from the Federal Reserve Board, www.federalreserve.gov/releases/h15/data/m/fp3m.txt. Money supply is M1, as of December of each year, and is not seasonally adjusted. From 1900 to 1914, it is from the Historical Statistics of the United States (1960), Series X-267. From 1915 to 1960, it is from Friedman and Schwartz (1963), pp. 708-744, col. 7. From 1961 to 2000, it is from the FRED II database of the St. Louis Fed. Nominal GDP from 1900 to 1928 is taken from the Historical Statistics of the United States, Colonial Times to Present (1970, F-1 p. 224). From 1929 to 2000, it is from the GDPA series from the Citibase database.

DATA SET

\begin{tabular}{|c|c|c|}
\hline Year & Interest rate & Money demand \\
\hline 1900 & 4.38 & 0.307540107 \\
\hline 1901 & 4.28 & 0.318792271 \\
\hline 1902 & 4.92 & 0.331018519 \\
\hline 1903 & 5.47 & 0.327729258 \\
\hline 1904 & 4.2 & 0.34139738 \\
\hline 1905 & 4.4 & 0.346533865 \\
\hline 1906 & 5.68 & 0.322752613 \\
\hline 1907 & 6.34 & 0.314868421 \\
\hline 1908 & 4.37 & 0.32833935 \\
\hline 1909 & 3.98 & 0.283203593 \\
\hline 1910 & 5.01 & 0.282691218 \\
\hline 1911 & 4.03 & 0.289860335 \\
\hline 1912 & 4.74 & 0.277106599 \\
\hline 1913 & 5.58 & 0.277727273 \\
\hline 1914 & 4.79 & 0.300906736 \\
\hline 1915 & 3.45 & 0.334925 \\
\hline 1916 & 3.42 & 0.323043478 \\
\hline 1917 & 4.74 & 0.303228477 \\
\hline 1918 & 5.87 & 0.272015707 \\
\hline 1919 & 5.42 & 0.279345238 \\
\hline 1920 & 7.37 & 0.252983607 \\
\hline 1921 & 6.53 & 0.296623563 \\
\hline 1922 & 4.42 & 0.308205128 \\
\hline 1923 & 4.97 & 0.269529965 \\
\hline 1924 & 3.9 & 0.288099174 \\
\hline 1925 & 4 & 0.280204082 \\
\hline
\end{tabular}




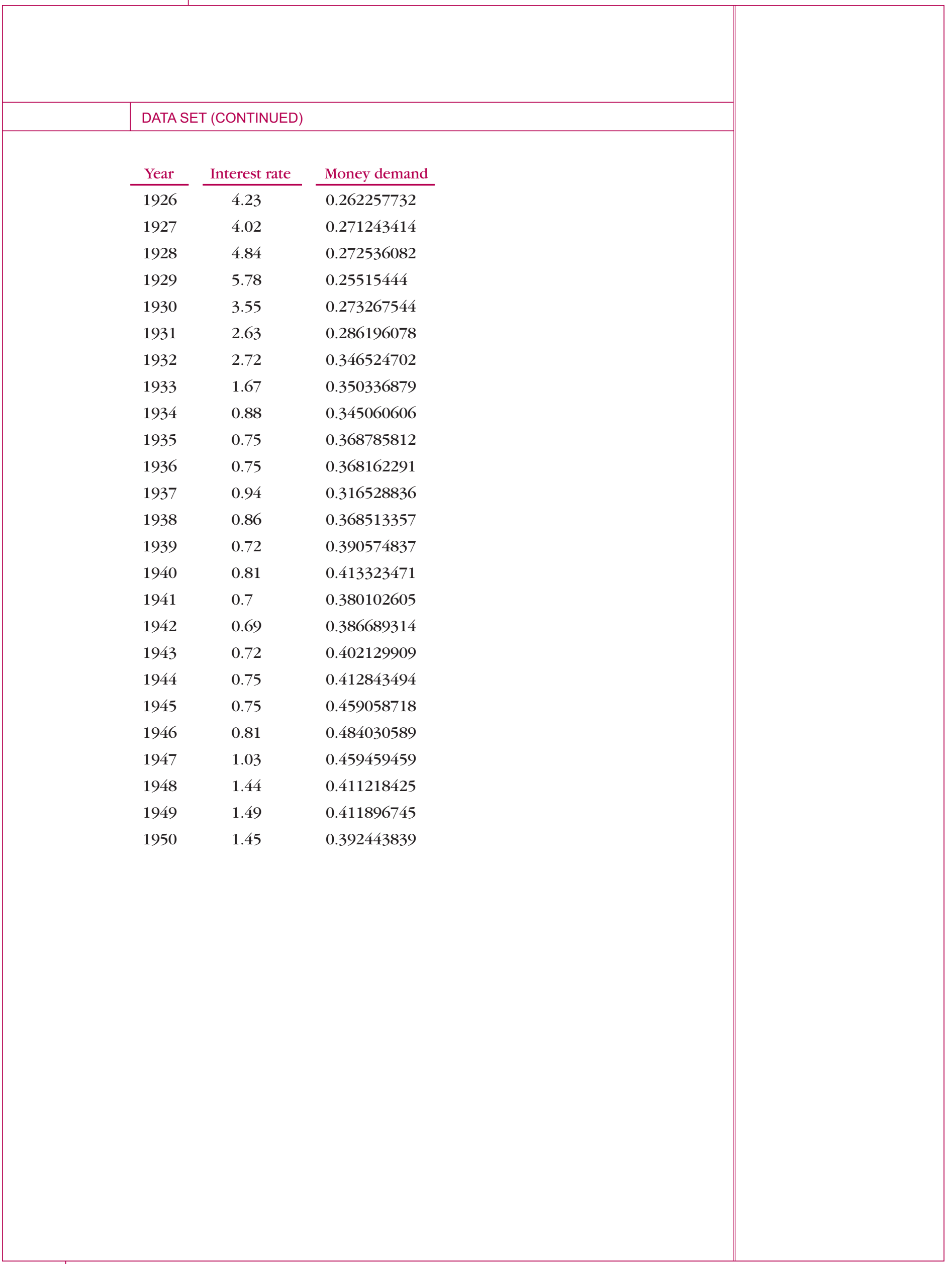




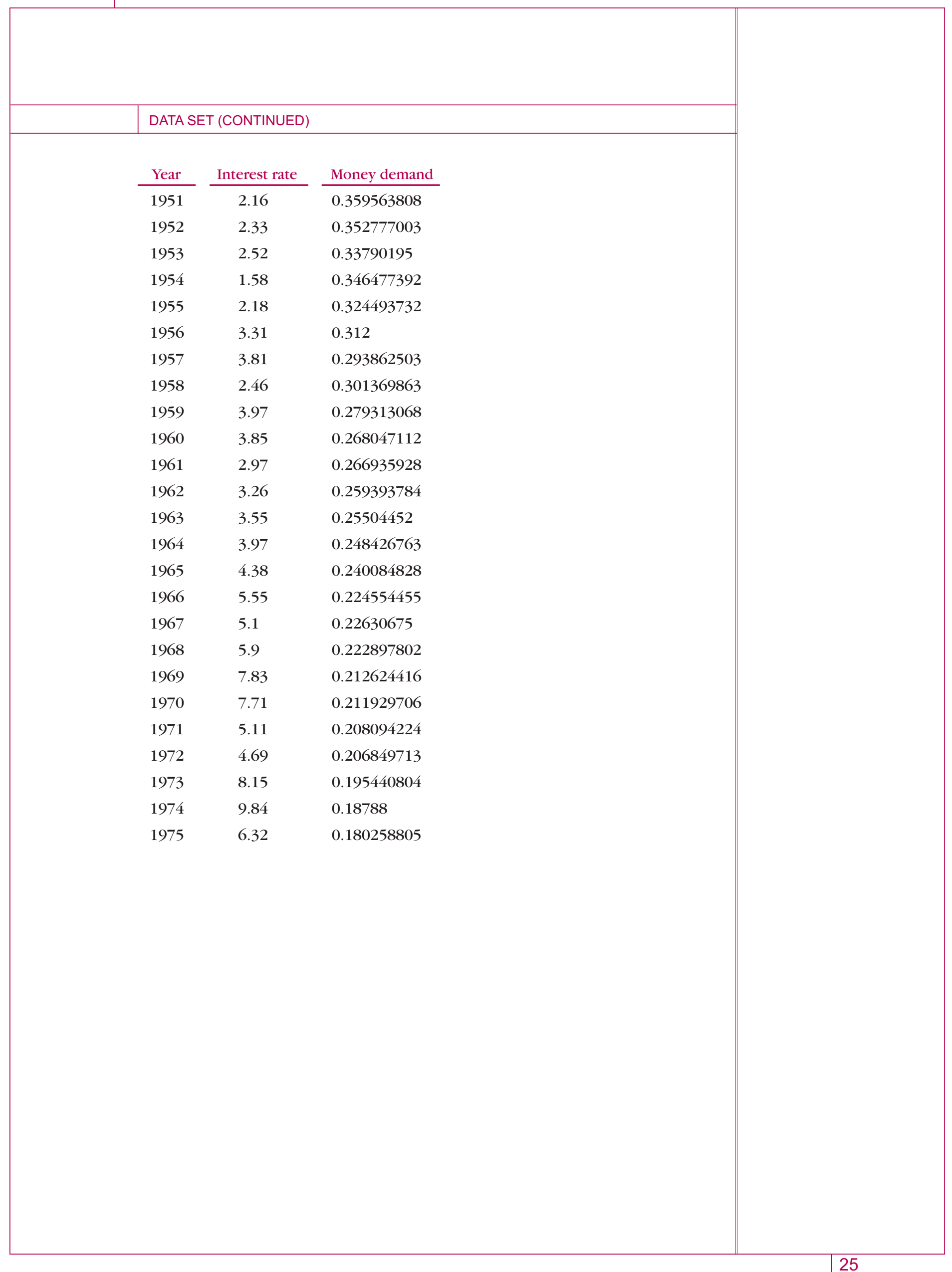




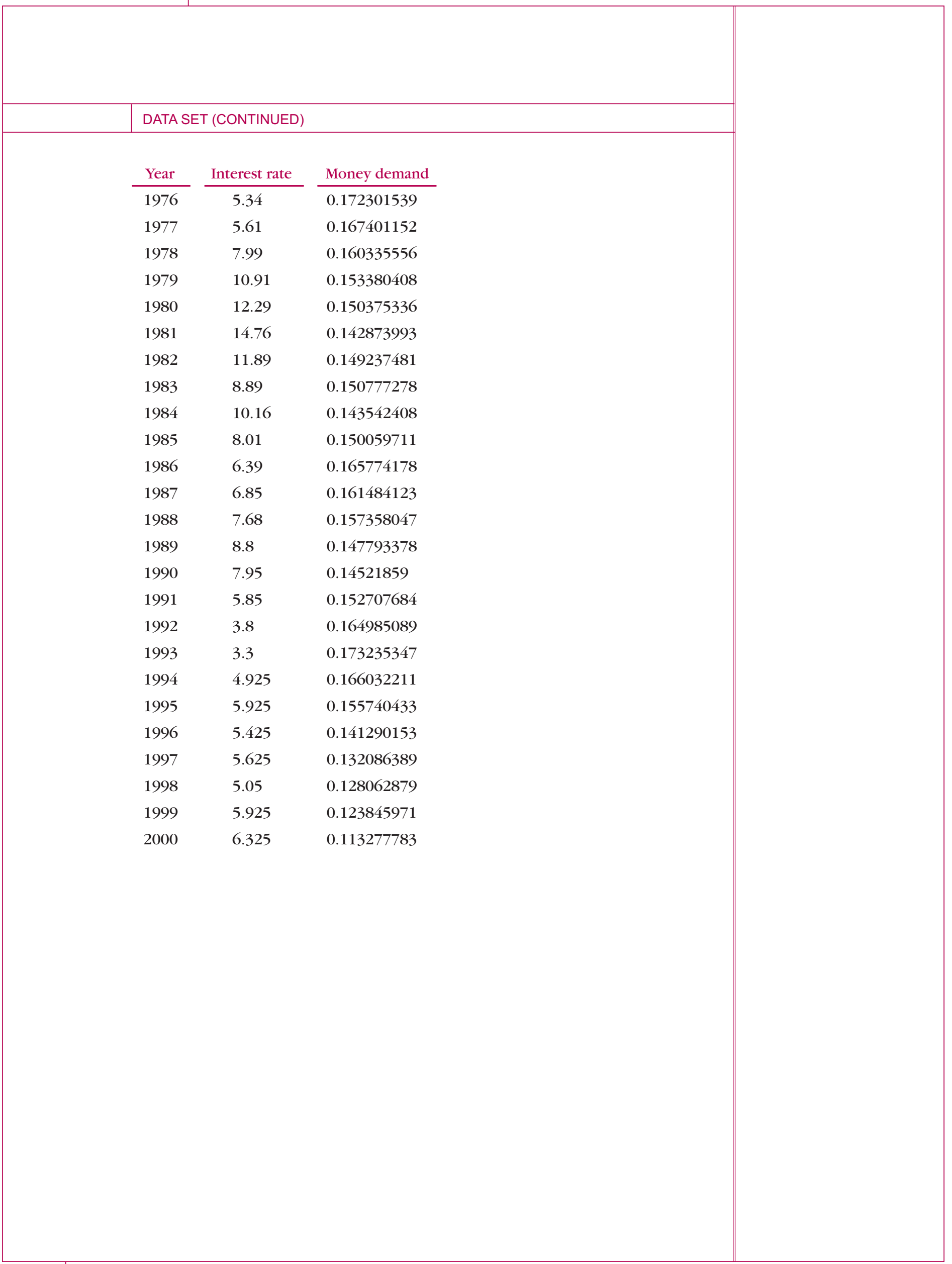




\section{Appendix 2: Parameter Values}

REGRESSIONS

\begin{tabular}{lccc} 
& $A$ & $\eta$ & $\mathrm{R}^{2}$ \\
\cline { 2 - 4 } & & & \\
Log-Log: $m(r)=A^{-\eta r}$ & 0.097835 & 0.29953 & 0.6238 \\
Semilog: $m(r)=A^{-\eta r}$ & 0.43056 & 11.027 & 0.6750 \\
Nonparametric & & & 0.6795
\end{tabular}

ESTIMATION OF THE SEARCH MODEL

(i) Proportional bargaining

\begin{tabular}{rrc}
$\theta$ & $A$ & $\eta$ \\
\hline 1.0 & 1.8248 & 0.14421 \\
0.8 & 1.9096 & 0.17601 \\
0.5 & 2.1876 & 0.26441 \\
0.3 & 2.8112 & 0.40346
\end{tabular}

(iii) Constant markup

\begin{tabular}{lcc}
\multicolumn{1}{c}{$\mu$} & \multicolumn{1}{c}{$A$} & $\eta$ \\
\hline 0 & 1.8249 & 0.14422 \\
0.1 & 1.0367 & 0.14423 \\
0.2 & 0.61861 & 0.14423
\end{tabular}

(v) Endogenous participation and Nash bargaining

\begin{tabular}{rlc}
$\theta$ & \multicolumn{1}{c}{$A$} & \multicolumn{1}{c}{$\eta$} \\
\hline 0.9 & 1.5699 & 0.53586 \\
0.8 & 1.6757 & 0.47177 \\
0.5 & 0.88848 & 0.27391 \\
0.3 & 0.48668 & 0.29534
\end{tabular}

(ii) Nash bargaining

\begin{tabular}{rrc}
$\theta$ & $A$ & $\eta$ \\
\hline 1.0 & 1.8249 & 0.14423 \\
0.8 & 1.8167 & 0.17676 \\
0.5 & 1.7722 & 0.26453 \\
0.3 & 1.6200 & 0.37878
\end{tabular}

(iv) Endogenous participation and proportional bargaining

\begin{tabular}{rrl}
$\theta$ & \multicolumn{1}{c}{$A$} & \multicolumn{1}{c}{$\eta$} \\
\hline 0.9 & 1.8166 & 0.50674 \\
0.8 & 1.5574 & 0.33898 \\
0.5 & 0.85057 & 0.2855 \\
0.3 & 0.44921 & 0.35956
\end{tabular}

(vi) Distributional effects

\begin{tabular}{rrc}
$p$ & $A$ & $\eta$ \\
\hline 1.0 & 2.1876 & 0.26441 \\
0.8 & 1.7461 & 0.26128 \\
0.5 & 1.0875 & 0.25658 \\
0.3 & 0.65116 & 0.25358
\end{tabular}




\section{References}

Aiyagari, Rao,Anton Braun, and Zvi Eckstein. "Transaction Services, Inflation, and Welfare," Journal of Political Economy, vol. 106 (1998), pp. 1274-1301.

Aruoba, Boragan, and Randall Wright. "Search, Money and Capital:A Neoclassical Dichotomy, Journal of Money, Credit, and Banking, vol. 35 (2003), pp. 1085-1106.

Aruoba, Boragan, Christopher Waller, and Randall Wright. "Money and Capital," unpublished manuscript (2004).

Bailey, Martin. "The Welfare Cost of Inflationary Finance," Journal of Political Economy, vol. 64 (1956), pp.93-110.

Berentsen,Aleksander, Guillaume Rocheteau, and Shouyong Shi."Friedman Meets Hosios: Efficiency in Search Models of Money," Federal Reserve Bank of Cleveland,Working Paper no. 04-08, 2004.

Brockman, Michael,Theo Glasser, and Eva Herrmann. "Locally Adaptive Bandwidth Choice for Kernel Estimators,"Journal of the American Statistical Association, vol. 88 (1993), pp. 1302-09.

Craig, Ben, and Guillaume Rocheteau. "State-Dependent Pricing, Inflation, and Welfare in Search Economies," Federal Reserve Bank of Cleveland, Working Paper no. 05-04, 2005.

Craig, Ben, and Christopher Waller. "Dollarization and Currency Exchange," Journal of Monetary Economics, vol. 51 (2004), pp. 671-89.

Cooley, Thomas, and Gary Hansen. "The Inflation Tax in a Real Business Cycle Model," American Economic Review 79 (1989), pp. 733-48.

Cooley, Thomas, and Gary Hansen. "The Welfare Costs of Moderate Inflations," Journal of Money, Credit and Banking, vol. 23 (1991), pp. 483-503.

Deviatov,Alexei, and Neil Wallace. "Another Example in which Lump-sum Money Creation Is Beneficial," Advances in Macroeconomics, vol. 1 (2001).

Dotsey, Michael, and Peter Ireland. "The Welfare Cost of Inflation in General Equilibrium," Journal of Monetary Economics, vol. 37 (1996), pp. 29-47.

Ennis, Huberto. "Search, Money, and Inflation under Private Information," Federal Reserve Bank of Richmond, Discussion Paper no. 142, 2004.

Faig, Miquel."Divisible Money in an Economy with Villages,” unpublished manuscript, 2004.

Fischer, Stanley. "Towards an Understanding of the Costs of Inflation: II," Carnegie-Rochester Conference Series on Public Policy, vol. 15 (1981), pp. 5-42. 
Friedman, Milton. "The Optimum Quantity of Money," in The Optimum Quantity of Money and Other Essays, Chicago:Aldine Publishing Company, 1969.

Hosios, Arthur. "On the Efficiency of Matching and Related Models of Search and Unemployment," Review of Economic Studies, vol. 57 (1990), pp. 279-98.

Kiyotaki, Nobuhiro, and Randall Wright. "On Money as a Medium of Exchange," Journal of Political Economy, vol. 97 (1989), pp. 927-54.

Kiyotaki, Nobuhiro, and Randall Wright."A Contribution to the Pure Theory of Money,"Journal of Economic Theory, vol. 53 (1991), pp. 215-35.

Kiyotaki, Nobuhiro, and Randall Wright. "A Search-Theoretic Approach to Monetary Economics," American Economic Review, vol. 83 (1993), pp. 63-77.

Kocherlakota, Narayana. "Optimal Monetary Policy: What We Know and What We Don't Know," International Economic Review, forthcoming.

Lagos, Ricardo, and Randall Wright. "A Unified Framework for Monetary Theory and Policy Analysis," Journal of Political Economy, forthcoming.

Levine, David."Asset Trading Mechanisms and Expansionary Policy,"Journal of Economic Theory, vol. 54 (1991), pp. 148-64.

Li, Victor. "The Optimal Taxation of Fiat Money in Search Equilibrium," International Economic Review, vol. 36 (1995), pp. 927-42.

Li,Victor."The Efficiency of Monetary Exchange in Search Equilibrium,"Journal of Money, Credit and Banking 29 (1997), pp. 61-72.

Lucas, Robert. "Discussion of: Stanley Fischer,Towards an Understanding of the Costs of Inflation: II," Carnegie-Rochester Conference Series on Public Policy, vol. 15 (1981), pp. 43-52.

Lucas, Robert.“Inflation and Welfare," Econometrica, vol. 68 (2000), pp. 247-74.

Marty,Alvin. "The Welfare Cost of Inflation:A Critique of Lucas and Bailey, Federal Reserve Bank of St. Louis, Review, vol. 81 (1999), pp. 41-6.

Molico, Miguel. "The Distribution of Money and Prices in Search Equilibrium," unpublished manuscript (1999).

Nash,John.“The Bargaining Problem,” Econometrica, vol. 18 (1950), pp. 155-62.

Reed, Robert, and Christopher Waller."Money and Risk Sharing," unpublished manuscript (2004).

Rocheteau, Guillaume, and Christopher Waller. "Bargaining and the Value of Money," Federal Reserve Bank of Cleveland, Working Paper no. 05-01 (2005). 
Rocheteau, Guillaume, and Randall Wright. "Inflation and Welfare in Models with Trading Frictions," in Monetary Policy in Low-Inflation Economies, edited by David E.Altig and Ed Nosal, Cambridge: Cambridge University Press, forthcoming.

Rocheteau, Guillaume, and Randall Wright."Money in Search Equilibrium, in Competitive Equilibrium, and in Competitive Search Equilibrium," Econometrica, vol. 73 (2005), pp. 175-202.

Siefert, Burkhardt, Michael Brockman, Joachim Engel, and Theo Gasser. "Fast Algorithms for Nonparametric Curve Estimation," Journal of Computational and Grapbical Statistics, vol. 3 (1994), pp. 192-213.

Shi, Shouyong. “A Divisible Search Model of Fiat Money," Econometrica, vol. 65 (1997), pp. 75-102.

Shi, Shouyong. "Search, Inflation, and Capital Accumulation," Journal of Monetary Economics, vol. 44 (1999), pp. 81-103. 


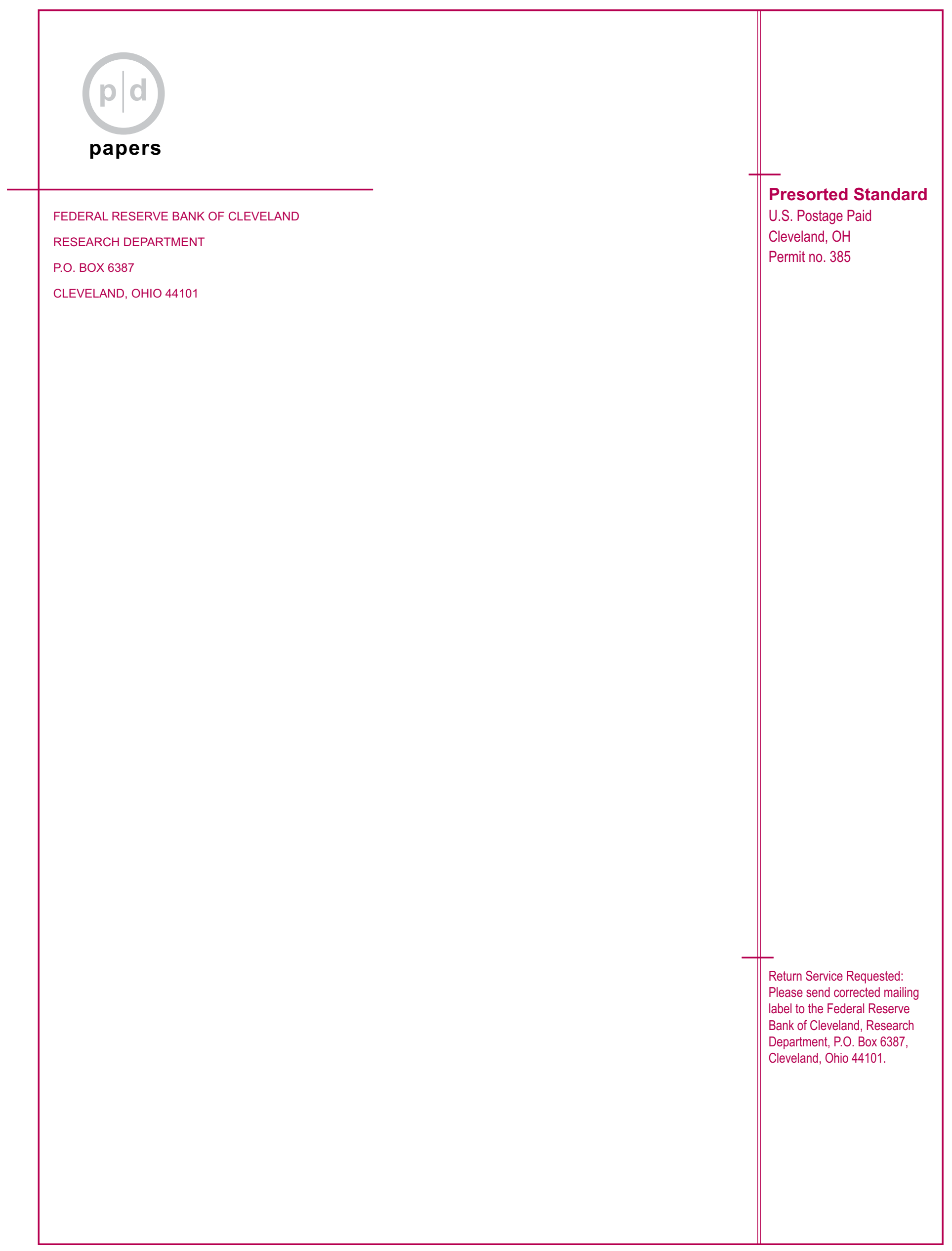

